\title{
Article \\ Changes in Digestive Microbiota, Rumen Fermentations and Oxidative Stress around Parturition Are Alleviated by Live Yeast Feed Supplementation to Gestating Ewes
}

\author{
Lysiane Dunière ${ }^{1,2} \mathbb{D}^{-}$, Damien Esparteiro ${ }^{1,2, \dagger}$, Yacine Lebbaoui ${ }^{1,2}$, Philippe Ruiz $^{2}{ }^{\oplus}$, Mickael Bernard ${ }^{3}$, \\ Agnès Thomas ${ }^{4}$, Denys Durand ${ }^{4}\left(\mathbb{D}\right.$, Evelyne Forano ${ }^{2}\left(\mathbb{B}\right.$ and Frédérique Chaucheyras-Durand ${ }^{1,2, *}$ \\ 1 Lallemand SAS, 19 rue des Briquetiers, BP 59, CEDEX, 31702 Blagnac, France; lduniere@lallemand.com (L.D.); \\ esparteiro.d@gmail.com (D.E.); ylebbaoui@lallemand.com (Y.L.) \\ 2 UMR (Unité Mixte de Recherches) 454 MEDIS (Microbiologie Environnement Digestif et Santé), INRAE \\ Université Clermont Auvergne, 63122 Saint-Genès Champanelle, France; philippe.ruiz@inrae.fr (P.R.); \\ evelyne.forano@inrae.fr (E.F.) \\ 3 UE (Unité Expérimentale) 1414 Herbipôle, INRAE (Institut National de Recherche pour l'Agriculture, \\ l'Alimentation et l'Environnement), Université Clermont Auvergne, 63122 Saint-Genès Champanelle, France; \\ mickael.bernard@inrae.fr \\ 4 UMR (Unité Mixte de Recherches) 1213 Herbivores, INRAE (Institut National de Recherche pour \\ l'Agriculture, l'Alimentation et l'Environnement), Université Clermont Auvergne, \\ 63122 Saint-Genès Champanelle, France; agnes.thomas@inrae.fr (A.T.); denis.durand@inrae.fr (D.D.) \\ * Correspondence: fchaucheyrasdurand@lallemand.com \\ † Present address: Faculté des Sciences et Techniques, Université de Brest, 29200 Brest, France.
}

Citation: Dunière, L.; Esparteiro, D.; Lebbaoui, Y.; Ruiz, P.; Bernard, M.; Thomas, A.; Durand, D.; Forano, E.; Chaucheyras-Durand, F. Changes in Digestive Microbiota, Rumen Fermentations and Oxidative Stress around Parturition Are Alleviated by Live Yeast Feed Supplementation to Gestating Ewes. J. Fungi 2021, 7, 447. https://doi.org/10.3390/jof7060447

Academic Editors: Craig Faulds and Putarak Chomnunti

Received: 30 March 2021

Accepted: 2 June 2021

Published: 4 June 2021

Publisher's Note: MDPI stays neutral with regard to jurisdictional claims in published maps and institutional affiliations.

Copyright: () 2021 by the authors Licensee MDPI, Basel, Switzerland This article is an open access article distributed under the terms and conditions of the Creative Commons Attribution (CC BY) license (https:// creativecommons.org/licenses/by/ $4.0 /)$.

\begin{abstract}
Background: In ruminants, physiological and nutritional changes occur peripartum. We investigated if gastro-intestinal microbiota, rumen metabolism and antioxidant status were affected around parturition and what could be the impact of a daily supplementation of a live yeast additive in late gestating ewes. Methods: Rumen, feces and blood samples were collected from 2 groups of 14 ewes one month and a few days before parturition, and 2 weeks postpartum. Results: In the control ewes close to parturition, slight changes in the ruminal microbiota were observed, with a decrease in the concentration $F$. succinogenes and in the relative abundance of the Fibrobacteres phylum. Moreover, a decrease in the alpha-diversity of the bacterial community and a reduced relative abundance of the Fibrobacteres phylum were observed in their feces. Control ewes were prone to oxidative stress, as shown by an increase in malondialdehyde (MDA) concentration, a lower total antioxidant status, and higher glutathione peroxidase (GPx) activity in the blood. In the yeast supplemented ewes, most of the microbial changes observed in the control group were alleviated. An increase in GPx activity, and a significant decrease in MDA concentration were measured. Conclusions: The live yeast used in this study could stabilize gastro-intestinal microbiota and reduce oxidative stress close to parturition.
\end{abstract}

Keywords: gestating ewes; parturition stress; rumen microbiota; fecal microbiota; live yeast; DNA sequencing; oxidative stress

\section{Introduction}

In dairy ruminant systems, the period around parturition is characterized by important hormonal, physiological, psychological, and nutritional changes and thus imposes severe challenges for the animal. Animals may develop metabolic stress if they fail to physiologically adapt to these challenges. The Negative Energy Balance (NEB) commonly encountered by the ruminant peripartum results in increased lipid mobilization and the generation of Reactive Oxygen Species (ROS). This alters the immune and metabolic status and ultimately leads to an increased risk of metabolic and infectious diseases such as enterotoxemia, ketosis, or mastitis during the transition period [1]. The dam also has 
a primary role in passive immune transfer through the colostrum [2] and in digestive microbiota inoculation [3] to the newborn.

At the gastrointestinal (GIT) level, distinct prepartum to postpartum shifts in the rumen bacterial community composition have been observed in cows between 3 weeks before and 3 weeks after calving, explained at least in part by the change in diet composition, notably by the increase in the proportion of readily fermentable carbohydrates, which is necessary to ensure the energy needs of the cow around parturition [4-6]. Such changes may put the animal at risk for rumen dysbiosis, leading, for instance, to acidosis, and leading to alterations in the rumen epithelium function [7]. Moreover, it has been shown that the microbial components from Gram negative bacteria, such as lipopolysaccharides (LPS), can be released in the disturbed rumen and can trigger a proinflammatory response as well as the production of reactive oxygen species [8,9]. In ewes, in which severe feed restriction in pregnancy may be observed, most ruminal fermentation parameters have been shown to decrease, associated with changes in the composition of the rumen epithelium-associated microbiota, and deleterious effects on the barrier function of the rumen epithelium have been reported [10].

For all these reasons, an optimal preparation of gestating ewes the few weeks before parturition is crucial to ensure the parturition process and the beginning of lactation in optimal conditions. Nutritional strategies that are able to prevent the development of oxidative processes during pregnancy [11], and an optimal management of the rumen function appear as key elements that participate in the maintenance of a good nutritional and health status in the gestating ewe. Several reports have demonstrated the benefits of live yeasts on rumen $\mathrm{pH}$ stabilization, microbial populations, and fiber digestibility [12-14] in sheep or cow studies.

In this work, we characterized the changes occurring around parturition on the rumen and fecal microbiota abundance, diversity and taxonomic composition, rumen fermentations, and oxidative stress. In addition, we studied the impact of live yeast (Saccharomyces cerevisiae CNCM I-1077, Levucell SC, Lallemand Animal Nutrition, Blagnac, France) supplementation prepartum with the hypothesis that this would represent an effective strategy to improve the rumen environment, prevent rumen dysbiosis, and protect animals against oxidative stress.

\section{Materials and Methods}

\subsection{Diets and Animals}

Twenty-eight gestating ewes (Ovis aries, Romane breed) were used for this study. All of them carried two or three fetuses. They were selected following an echographic evaluation a few weeks before the start of the trial and were assigned to two groups (control = C, supplemented $=$ SC) which were balanced homogeneously according to age, parity, body condition score, and live weight.

One month and a half before the estimated date of parturition, the ewes were transferred from the farm unit to a room equipped with Biocontrol CFRI systems (Biocontrol, Rakkestad, Norway) which allowed for the control of the concentrate intake, to ensure that ewes received the full yeast treatment. Indeed, because the yeast supplement was incorporated into the experimental concentrate, it was important to ensure that each animal had the same quantity of concentrate ingested, and at the same time of the day. The ewes were identified by means of ear RFID (radio frequency identification) transponders for specific access to the manger. The ewes were progressively adapted to the concentrate during the month before the start of the trial, by increasing the amount of concentrate fed daily up to $800 \mathrm{~g} / \mathrm{d} /$ animal. Then, until parturition, each ewe received this fixed amount of concentrate (Moulin de Massagettes, Massagettes, France, Table S1) daily, which was distributed once at 8:00 am, and which was followed by $2 \mathrm{~kg}$ of meadow hay. Good quality water was offered ad libitum. The nutritional composition of the diet is detailed in the Supplementary Materials section, Table S2. 
After 2 weeks of adaptation to the BioControl system and to this diet, the two groups received their allocated experimental concentrate, the only difference being the incorporation of the live yeast product in the supplemented group. The live yeast product Saccharomyces cerevisiae CNCM I-1077 (Levucell SC TITAN, Lallemand SAS, Blagnac, France) was a coated formulation included with the concentrate ingredients during the pelletization process, which allows for the protection of live yeast cells during the concentrate production. The rate of inclusion in the concentrate was calculated to bring $8 \times 10^{9} \mathrm{CFU}$ per day per individual. A few days before their estimated date of parturition, the ewes were transferred to a maternity unit which was split into two large pens separated by a concrete wall, to ensure that no contact could occur between the groups. The bedding was made of straw. The animals were then kept in these pens until the end of the experiment. The weight of the offspring was recorded within the first hour following the birth.

After parturition, the concentrate was not supplemented anymore with the live yeast product. The composition of the postpartum diet was modified to meet the requirements of the dam in order to feed only one lamb (the other one was directed to an artificial milk feeding system). So, each ewe was fed with $600 \mathrm{~g}$ of concentrate and $3 \mathrm{~kg}$ of meadow hay, covering a bit more than $135 \%$ of its energy needs.

The total yeast enumeration was performed in experimental concentrates throughout the study (the day of concentrate delivery, and 15, 30, and 60 days after) to ensure that the concentration of yeast met the expectations. Briefly, $30 \mathrm{~g}$ of pellets were ground for $30 \mathrm{sec}$ in a Waring blender, then suspended in peptone water, ground again for $1 \mathrm{~min}$ in the Waring blender, transferred in a stomacher, and homogenized for $1 \mathrm{~min}$ in a sterile filter bag. One milliliter was then collected from the bag and diluted in $9 \mathrm{~mL}$ of sterile peptone water. Serial dilutions were performed and plated onto Sabouraud + Chloramphenicol agar Petri dishes (AES Chemunex/BioMérieux, Combourg, France). Duplicate plates per dilution were incubated during $48 \mathrm{~h}$ at $30^{\circ} \mathrm{C}$ before colonies could be counted. In the control concentrate, no viable yeast was detected on the agar plates. In the supplemented concentrate, the average concentration from the duplicate analysis was $1.03 \times 10^{7} \mathrm{CFU}$ per gram of feed, so the concentration matched the expectations (i.e., with $800 \mathrm{~g}$ fed daily, to bring $8 \times 10^{9} \mathrm{CFU}$ per head).

The animal trial was conducted at the animal facilities of INRAE Herbipôle Experimental Unit UE1414 (Clermont Auvergne Rhône Alpes, Saint-Genès Champanelle, France). The procedures on the animals were carried out in accordance with the guidelines for animal research of the French Ministry of Agriculture and all other applicable national and European guidelines and regulations for experimentation with animals (see https:/ / www.legifrance.gouv.fr/loda/id/JORFTEXT000027038013/ for details, accessed on 3 June 2021).

The protocol was favorably evaluated by the Regional Ethics Committee for Animal Experimentation C2EA-02 and the French Research Ministry authorized its implementation with the reference number 14981-2018050417167566V3 (21 December 2018).

\subsection{Sample Collection}

All samples were collected at different periods: the week before the start of the supplemented concentrate distribution i.e., three to four weeks before parturition (BS for 'before live yeast supplementation'), a few days (8 on average) before parturition (Pa for 'close to parturition'), and two weeks after parturition (PP for 'postpartum'). The rumen fluid $(\sim 100 \mathrm{~mL})$ was collected the same day for all the ewes before the morning feeding via a stomach PVC tube which was connected to a manual pump. The retention of the ewes was smooth, and the tube was carefully introduced in the mouth and pushed gently inside the rumen. The regurgitated digestive contents were retrieved in a sterile container. The quality of the sample was visually checked (absence of a visible amount of saliva, no trace of blood). Immediately after sampling, the $\mathrm{pH}$ was recorded, and the samples were brought back to the laboratory where they were processed. One portion was treated for analysis of volatile fatty acids (VFA), the other was frozen at $-20^{\circ} \mathrm{C}$ for microbial analysis 
with molecular methods. The fecal samples ( $\sim 50 \mathrm{~g})$ were obtained by rectal collection and rapidly frozen at $-20{ }^{\circ} \mathrm{C}$ for further analysis.

Whole blood samples were collected two days after the collection of the digestive samples via venipuncture in the jugular vein, and plasma samples were prepared for further oxidative stress biomarkers, as previously described [15], and stored in light safe Eppendorf tubes at $-80^{\circ} \mathrm{C}$ until analysis.

\subsection{Measured Parameters}

The rumen $\mathrm{pH}$ was measured immediately after sampling using a laboratory $\mathrm{pH}$ probe. VFA analysis was performed on the rumen samples as previously described [16]. The rumen fluid was centrifuged for $10 \mathrm{~min}$ at $10,000 \times g, 4^{\circ} \mathrm{C}$. DNA was extracted from $250 \mathrm{mg}$ of rumen centrifuged pellets or from $150 \mathrm{mg}$ of fecal contents using the Quick DNA Fecal/Soil Microbe kit (Zymo Research, Irvine, CA, USA). DNA yield and quality were determined after Nanodrop 1000 spectrophotometric quantification. The DNA extracts were stored at $-20{ }^{\circ} \mathrm{C}$ until analysis.

The microbial populations were quantified using the qPCR method, with specific primer sets and PCR conditions targeting the ribosomal RNA genes of total bacteria, protozoa, archaea, the yeast $S$. cerevisiae, specific bacterial groups, genus, or species according to the digestive sample (rumen fluid or feces) and the Internal transcribed spacer 1 (ITS1) of rumen fungi. The PCR targets and primers are summarized in the Supplementary Materials section, Table S3.

Standards were used to determine the absolute abundance of the microbial groups, expressed as the $\log _{10}$ number of gene copies per microgram of the pelleted rumen or feces. For total bacteria, cellulolytic bacteria, and methanogenic archaea, the standard curves were prepared according to Mosoni et al. [17]. For protozoa, the standard curve was prepared according to Bayat et al. [18]. For each target, a standard curve was prepared from $10^{2}$ to $10^{9}$ copies by serial dilution. For $S$. cerevisiae quantification, the standard curve was constructed using DNA obtained from Levucell SC20 commercial product. A PBS-suspension of $10^{8} \mathrm{CFU} / \mathrm{g}$ was prepared (total CFU/g in the commercial product was previously checked) and DNA extraction was performed on this suspension. Decimal dilutions of DNA were performed to obtain a range of corresponding cell concentrations of $10^{7}$ to $10^{3} \mathrm{CFU} / \mathrm{g}$. It was then possible to obtain a standard curve relating the yeast cell concentrations and the Cycle threshold $(\mathrm{Ct})$ values. The efficiency of the qPCR method for each target varied between 97 and $102 \%$ with a slope from -3.0 to -3.4 and a regression coefficient above 0.95 .

Microbiota diversity and taxonomic composition were analyzed by a 16S/18S amplicon metagenomic sequencing approach. DNA samples were quantified with a Qubit spectrophotometer to adjust the concentrations to at least $20 \mathrm{ng} / \mu \mathrm{L}$, and a volume of $30 \mu \mathrm{L}$ per sample was sent to the Novogene sequencing platform (Novogene Co. Ltd., Cambridge, UK). DNA sequencing was performed on a subset of samples from 6 ewes per group balanced in terms of age, weight, and body condition score, for each sampling time considered. The diversity and composition of rumen/fecal microbiota were studied using the high throughput sequencing Illumina MiSeq (Illumina, San Diego, CA, USA) method $(2 \times 250 \mathrm{nt}$ paired ends). The primer sets used, and the rDNA regions targeted are indicated in the Supplementary Materials section, Table S4. Libraries construction and MiSeq Illumina sequencing were carried out following the protocols validated by Novogene. The paired-end reads were merged and filtered, and the chimera were removed using FLASH, the Qiime quality control process and the UCHIME algorithm, respectively [19-22]. A sequence analysis was performed by the Uparse software with $\geq 97 \%$ similarity threshold [23,24]. For each OTU representative sequence, Mothur software was performed against the SSUrRNA database of the SILVA Database (Threshold:0.8 1) [25,26]. Subsequent analyses of alpha diversity and beta diversity were performed with $\mathrm{R}$ studio software using Phyloseq and Microbiome R packages $[27,28]$ on normalized samples. The differential abundance analysis at OTU level was performed with the DESeq2 package [29]. 
The measurement of the ferric reducing ability of plasma (FRAP) was completed by the assay based on the method of Benzie and Strain [30] but was slightly modified. Briefly, $30 \mu \mathrm{L}$ of sample and $90 \mu \mathrm{L}$ of water were pipetted in the microplate in triplicate.

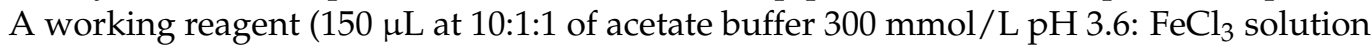
$20 \mathrm{mmol} / \mathrm{l}: 2,4$,6-tripyridyl-s-triazine solution $10 \mathrm{mmol} / \mathrm{L}$ ) was added in each well, and the reaction mixture was incubated for $30 \mathrm{~min}$ at $37^{\circ} \mathrm{C}$. The absorbance was measured at $593 \mathrm{~nm}$. The GPx activity was measured spectrophotometrically according to Agergaard and Jensen [31].

The indicators of energy and lipid metabolism were measured by spectrophotometry as indicated by Delosière et al. [32]. The measurement of malondialdehyde (MDA) was determined in the plasma samples by high performance liquid chromatography (HPLC) followed by UV spectrophotometry [33].

The indicators of liver status (IU/L) were measured directly from plasmatic samples by spectrophotometry using specific kits according to the manufacturers' recommendations, as described in Delosière et al. [32]. The aminotransferases were measured with a Sobioda kit (ALAT, Montbonnot-Saint-Martin, France) and a Biodirect TGO kit (ASAT, Lavilleneuve, France). The phosphatase alkaline was measured with a ThermoFisher Scientific kit (PAL, Waltham, MA, USA), and gamma-glutamyl transpeptidase with a Biodirect kit (GGT, Lavilleneuve, France).

\subsection{Statistical Analyses}

Graphical representations and statistical analyses were performed using GraphPad Prism v8.4.3. The results are presented as the mean \pm SD. The animals were assigned to C or SC groups according to age, parity, body condition score, and live weight. However, significant differences $(p<0.05)$ or tendency $(p<0.10)$ were observed BS for several parameters (i.e., pH, Acetate, Propionate, and relative abundance of Euryarchaeota, Entodinium and total anaerobic fungi in rumen; alpha diversity indices and relative abundance of Bacteroidetes in feces; MDA and FRAP in blood). Consequently, a new variable $\mathrm{Y}_{\text {diff }}$ was defined for each parameter considered. $Y_{\text {diff }}$ corresponded to the subtraction of the initial $\mathrm{BS}$ values to the $\mathrm{Pa}$ and the PP values. A linear mixed model with repetitions was then applied to these new $\mathrm{Y}_{\text {diff }}$ variables to evaluate the effect of group and time factors and their interaction. This "anova of change" model has been previously recommended by Van Breukelen [34] in order to limit the bias observed in the case of preexisting groups presenting significantly different baselines. For some parameters, the data could not fit the chosen mixed model i.e., when the data were not normally distributed and the nonparametric Mann-Whitney (MW) test was thus applied to compare the C and SC groups at each time. Therefore, statistical analyses are presented either in tables summarizing the $p$-values from the linear mixed model, or in tables summarizing the $p$-values from the Mann-Whitney tests in the case of data that were not normally distributed. For the oxidative parameters, the samplings were performed only at $\mathrm{BS}$ and $\mathrm{Pa}$, and an unpaired $t$-test without assuming an equal SD (Welch test) was performed on the normalized $\mathrm{Pa}$ values. The statistical significance was determined at a $p$-value $<0.05$ and trends were discussed when $p<0.10$. To ease comprehension, graphical representations of the $Y_{\text {diff }}$ variables are presented in the Supplementary Materials section only for the parameters with $p$-values $\leq 0.10$.

\section{Results}

\subsection{Rumen $\mathrm{pH}$ and VFAs}

The mean rumen $\mathrm{pH}$, which was measured before the morning feeding, was quite stable throughout the whole experimental period (Figure $1 \mathrm{~A}$ ). The $\mathrm{pH}$ values were close to neutrality or even higher, maybe due to small saliva contamination during the rumen sampling through the oral tubing. No effect of either the period or the treatment was observed on the rumen $\mathrm{pH}(p>0.05)$. 

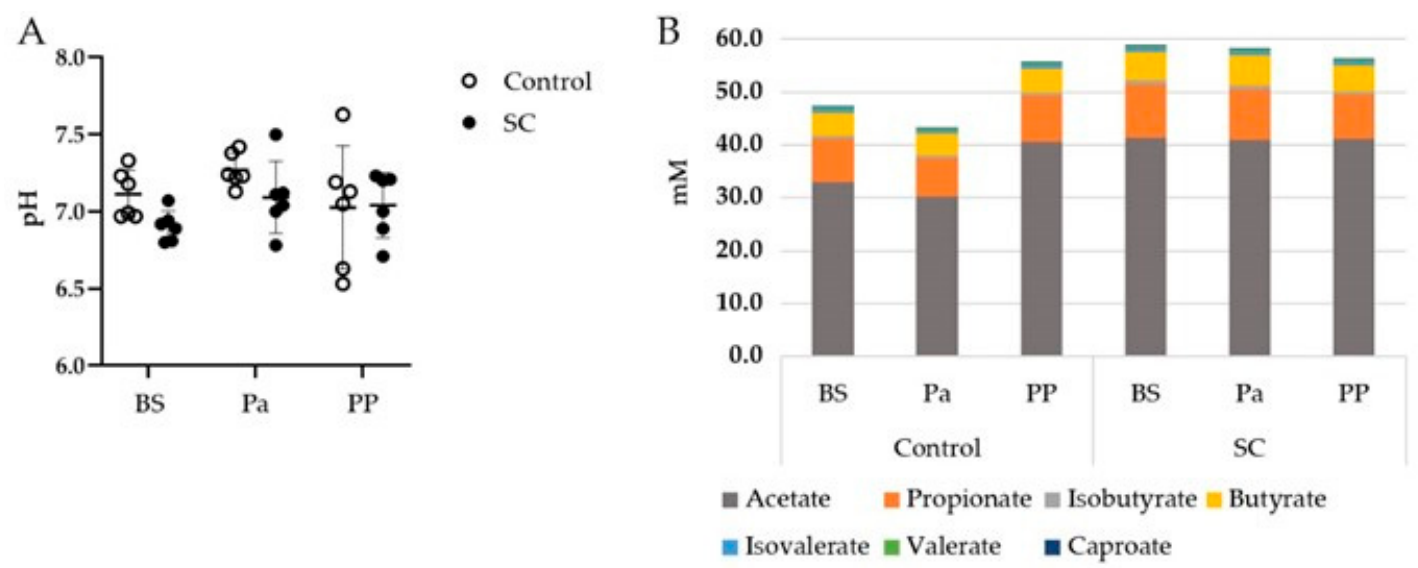

Figure 1. (A) Evolution of the rumen $\mathrm{pH},(\mathbf{B})$ Mean VFA concentrations ( $\mathrm{mM})$ in the rumen contents of the ewes from the control or SC groups ( $n=6$ per group) over the experimental period. BS = before supplementation of $\mathrm{SC}, \mathrm{Pa}=\mathrm{close}$ to parturition, $\mathrm{PP}=2$ weeks postpartum.

The total VFA, acetate, propionate, and butyrate concentrations presented different evolutions between the control and SC groups (Figure 1B). Indeed, the total VFA and acetate concentrations decreased at $\mathrm{Pa}$ and increased at PP in the control group while they remained stable in the SC group (Table 1, Figure S1). A significant time effect was observed for Valerate and Caproate with a tendency of decrease PP for Valerate.

Table 1. $p$-values associated with the VFA statistical analysis with a linear mixed model.

\begin{tabular}{cccc}
\hline Measured Parameter & Group & Time & Interaction $\mathbf{G} \times \mathbf{T}$ \\
\hline Total VFA & 0.309 & 0.164 & 0.060 \\
\hline Acetate & 0.357 & 0.080 & 0.086 \\
\hline Propionate & 0.131 & 0.722 & 0.047 \\
\hline Butyrate & 0.569 & 0.647 & 0.055 \\
\hline Isobutyrate & 0.891 & 0.168 & 0.136 \\
\hline Isovalerate & 0.870 & 0.607 & 0.131 \\
\hline Valerate & 0.535 & 0.002 & 0.085 \\
\hline Caproate & 0.142 & 0.002 & 0.180 \\
\hline
\end{tabular}

\subsection{Rumen and Feces Microbiota}

\subsection{1. qPCR Results}

In the rumen, Saccharomyces cerevisiae was detected in both groups before supplementation (5.88 \pm 0.49 and $5.65 \pm 0.37 \log _{10}$ copies/g of pelleted rumen content for the control and SC groups, respectively, Table 2) in the SC group. A strong statistical effect of both time and group factors was observed as the abundance of this species increased significantly in the SC group in the samples collected just before parturition (Figure S2): it went up to $7.49 \pm 0.34 \log _{10}$ copies/g of pelleted rumen content, whereas it remained stable in the control group (6.11 $\pm 0.60 \log _{10}$ copies/g of pelleted rumen content). Two weeks after parturition, the concentrations of Saccharomyces cerevisiae decreased in the SC group to values comparable with the control group, and to values quite similar to those found at the start of the trial. 


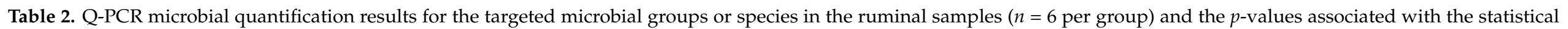

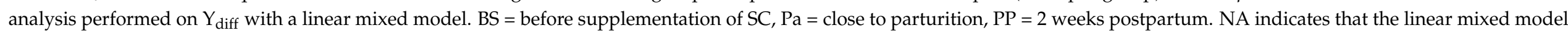
was not applied to these data.

\begin{tabular}{|c|c|c|c|c|c|c|c|c|c|}
\hline \multirow{2}{*}{$\begin{array}{c}\log _{10} \text { of Copy Numbers/g } \\
\text { Pelleted Rumen Content }\end{array}$} & \multicolumn{2}{|c|}{ BS } & \multicolumn{2}{|c|}{$\mathbf{P a}$} & \multicolumn{2}{|c|}{ PP } & \multicolumn{3}{|c|}{$p$-Value from Linear Mixed Model on $\mathrm{Y}_{\text {diff }}$} \\
\hline & Control & SC & Control & SC & Control & SC & Group & Time & Interaction $\mathrm{G} X \mathrm{~T}$ \\
\hline Total bacteria & $10.86 \pm 0.09$ & $10.83 \pm 0.18$ & $10.91 \pm 0.11$ & $10.91 \pm 0.24$ & $10.78 \pm 0.07$ & $10.78 \pm 0.17$ & 0.648 & 0.019 & 0.941 \\
\hline Ruminococcus flavefaciens & $7.72 \pm 0.32$ & $8.09 \pm 0.42$ & $8.03 \pm 0.16$ & $7.79 \pm 0.29$ & $7.8 \pm 0.12$ & $7.8 \pm 0.23$ & 0.013 & 0.181 & 0.152 \\
\hline Ruminococcus albus & $6.64 \pm 0.16$ & $6.9 \pm 0.24$ & $6.85 \pm 0.35$ & $6.99 \pm 0.47$ & $7.16 \pm 0.25$ & $7.19 \pm 0.22$ & 0.157 & 0.003 & 0.403 \\
\hline Fibrobacter succinogenes & $9.61 \pm 0.17$ & $9.37 \pm 0.38$ & $9.28 \pm 0.10$ & $9.32 \pm 0.19$ & $9.32 \pm 0.38$ & $9.24 \pm 0.16$ & NA & NA & NA \\
\hline Prevotella & $8.93 \pm 0.12$ & $8.94 \pm 0.19$ & $8.96 \pm 0.11$ & $9.01 \pm 0.16$ & $8.84 \pm 0.17$ & $8.76 \pm 0.18$ & 0.831 & 0.013 & 0.315 \\
\hline Megasphaera elsdenii & $2.48 \pm 0.32$ & $2.42 \pm 0.17$ & $2.41 \pm 0.5$ & $2.68 \pm 0.17$ & $2.55 \pm 0.32$ & $2.70 \pm 0.31$ & 0.438 & 0.234 & 0.825 \\
\hline Methanogenic Archaea & $7.66 \pm 0.23$ & $7.87 \pm 0.23$ & $7.95 \pm 0.29$ & $8.07 \pm 0.19$ & $7.85 \pm 0.41$ & $8.02 \pm 0.21$ & 0.726 & 0.129 & 0.923 \\
\hline Protozoa & $9.84 \pm 0.14$ & $9.52 \pm 0.66$ & $9.92 \pm 0.34$ & $9.33 \pm 0.52$ & $9.51 \pm 0.15$ & $9.28 \pm 0.31$ & 0.786 & 0.106 & 0.200 \\
\hline Anaerobic fungi & $6.27 \pm 0.37$ & $6.19 \pm 0.64$ & $6.36 \pm 0.71$ & $6.13 \pm 0.49$ & $5.94 \pm 0.72$ & $6.16 \pm 0.39$ & 0.819 & 0.486 & 0.426 \\
\hline S. cerevisiae & $5.89 \pm 0.49$ & $5.65 \pm 0.38$ & $6.12 \pm 0.6$ & $7.49 \pm 0.34$ & $5.6 \pm 0.18$ & $5.91 \pm 0.54$ & 0.027 & 0.001 & 0.003 \\
\hline
\end{tabular}


The total bacteria concentration was little affected over time as it very slightly increased $(p<0.05)$ just before parturition in both groups and decreased postpartum (Table 2, Figure S2). The concentration of Prevotella sp. decreased postpartum, whatever the group $(p<0.05)$. Fibrobacter succinogenes was much more abundant than the two Ruminococcus species, with concentrations above $9 \log _{10} 16 \mathrm{~S}$ copies/g of pelleted rumen content and represented $\sim 5 \%$ of the total bacteria population. The significant difference in the $R$. flavefaciens concentration in the SC group compared to the control group was mainly due to a high BS average while R. albus was increasing over time in both groups. In the control group, F. succinogenes abundance decreased by 53.2\% from BS to $\mathrm{Pa}$, then slightly increased at PP, while it decreased by only $18.7 \%$ from BS to Pa in the SC group to finally reach $74.1 \%$ of its initial abundance at PP (Table 2). However, these differences were not found to be significant ( $p=0.999$ and $p=0.523$ at Pa and PP respectively, Mann-Whitney test between the $\mathrm{C}$ and SC groups).

In the fecal samples, the abundance of Saccharomyces cerevisiae was quite similar to that found in the rumen (Supplementary Materials, Table S5, Figure S3) with a significant effect of time $(p<0.001)$, group $(p=0.016)$, and interaction $(p=0.002)$ according to the linear mixed model. A higher concentration of $S$. cerevisiae was observed in the SC samples collected just before parturition. The Q-PCR results on the other targets in the feces are presented in the Supplementary Materials section in Table S5. They did not differ according to the time and the group or their interaction $(p>0.05)$.

The concentration of methanogenic Archaea was $8 \log _{10}$ mcr A gene copy numbers/g, which was similar to that found in the rumen. Escherichia coli was quantified between 8 and $9 \log _{10} 16 S$ gene copy numbers $/ g$, which represented $0.13 \%$ of the total bacteria concentration. Faecalibacterium prausnitzii was quantified at the same level. Regarding the fibrolytic microorganisms, anaerobic fungi were detected at less than $5 \log _{10}$ ITS copies/g, so 1 to $2 \log _{10}$ lower than the concentrations found in the rumen, and Fibrobacter succinogenes was weakly detected at a level close to $6 \log _{10} 16 \mathrm{~S}$ gene copies/g, representing $0.001 \%$ of the total bacterial population.

\subsubsection{S-DNA Sequencing Results}

\section{Alpha and beta diversity measures}

A great variability between individuals was noticed in the alpha diversity measures of the rumen bacterial communities whatever the group and physiological stage (Figure S4A). No significant difference was measured overall between the control and the SC groups (Table 3). However, there was a significant time effect, indicating a decrease in the richness and evenness at $\mathrm{Pa}$ followed by an increase at PP. No group effect was observed for the InvSimpson index ( $p>0.05$, Mann-Whitney test on normalized values).

Table 3. $p$-values associated with the statistical analysis of the alpha diversity indexes of the bacterial and archeal communities in the ruminal samples with a linear mixed model.

\begin{tabular}{cccc}
\hline Alpha-Div Indexes & Group & Time & $\mathbf{G} \times \mathbf{T}$ \\
\hline Observed OTUs & 0.589 & 0.001 & 0.626 \\
\hline Shannon & 0.851 & 0.003 & 0.178 \\
\hline
\end{tabular}

Less variability between the individuals was observed in the fecal diversities compared to the ruminal diversities (Figure S4B). A significant decrease in richness and evenness was noticed in the Control group at parturition, compared to the SC group (Table 4).

The beta diversity was also studied for both the ruminal and fecal communities using the Bray-Curtis dissimilarity matrix (Figure 2). The ruminal communities were rather close to each other between the individuals for a given physiological stage. No treatment effect could be observed. The fecal microbial community structure from the control group at BS appeared very different from the ones analyzed afterwards (Permanova analysis, $p<0.05$ ). In the SC group, the structure was more stable. 
Table 4. $p$-values associated with the statistical analysis of the alpha diversity indexes of the bacterial and archeal communities in the fecal samples with a linear mixed model.

\begin{tabular}{cccc}
\hline Alpha-Div Indexes & Group & Time & $\mathbf{G} \times \mathbf{T}$ \\
\hline Observed OTUs & 0.017 & 0.010 & 0.335 \\
\hline Shannon & 0.013 & 0.264 & 0.229 \\
\hline
\end{tabular}
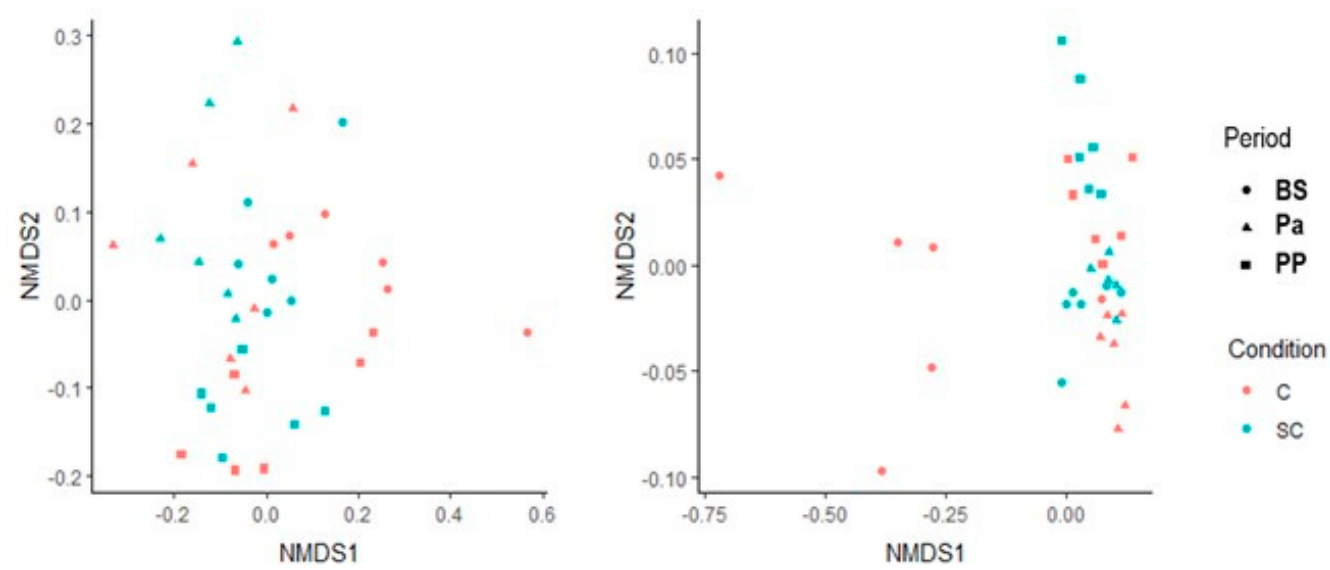

Figure 2. Non-metric multidimensional scaling representation for the bacterial and archaeal communities in the ruminal (left) and the fecal (right) samples. Circle $=\mathrm{BS}$; triangle $=\mathrm{Pa}$, square $=\mathrm{PP}$.

Relative abundances of the main taxonomic groups

Almost $98 \%$ of the $16 \mathrm{~S}$ sequences were assigned to nine main phyla (Figure 3). Among these nine phyla, Bacteroidetes was largely dominant, followed by Firmicutes and Fibrobacteres.

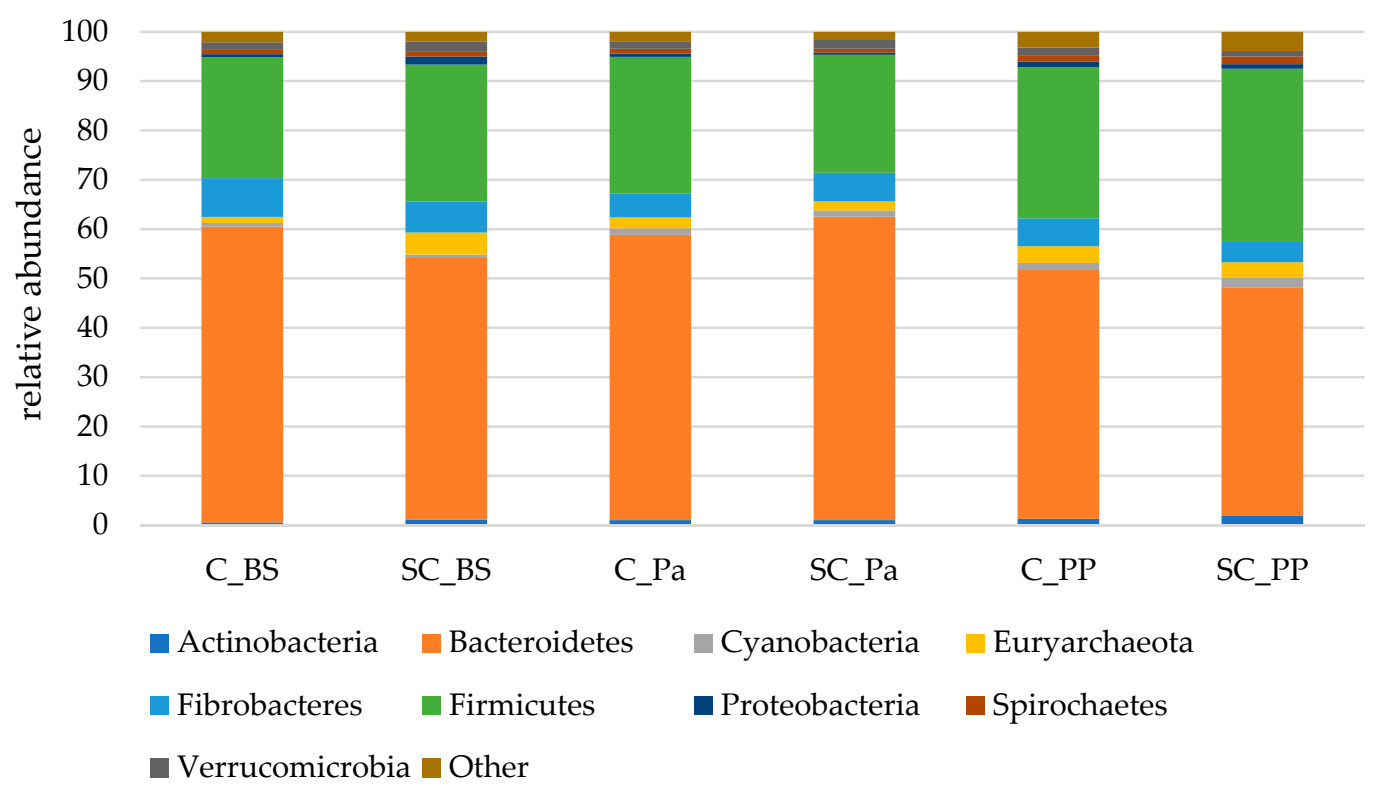

Figure 3. The relative abundances of the main bacterial and archaeal phyla in the rumen contents of both the experimental groups (Control C and Supplemented SC, $n=6$ per group) BS (before supplementation), Pa (close to parturition) and PP (2 weeks postpartum).

A significant decrease in the Bacteroidetes phylum was observed in the ruminal contents only after parturition (PP) while a tendency for an increase in Actinobacteria was observed (Table 5, Figure S5). Significant time effects were observed on Proteobacteria and 
Spirochaetes which were slightly increased at postpartum in both groups. A lower relative abundance of Euryarchaeota was observed in the SC group at Pa, indicating a decrease during the supplementation period. The relative abundance of Verrucomicrobia was lower in the SC group postpartum $(p=0.051)$ according to the Mann-Whitney test on normalized values. Although non-significant, a stronger decrease in Fibrobacteres was observed from BS to Pa in the control group ( $-38 \%$, from $7.9 \%$ to $4.9 \%)$ than in the SC group ( $-8 \%$, from $6.3 \%$ to $5.8 \%)$.

Table 5. $p$-values associated with the statistical analysis of the relative abundances of the bacterial and archaeal communities in the ruminal samples with a linear mixed model.

\begin{tabular}{cccc}
\hline Phylum & Group & Time & G $\times$ T \\
\hline Actinobacteria & 0.589 & 0.039 & 0.503 \\
\hline Bacteroidetes & 0.225 & 0.044 & 0.445 \\
\hline Cyanobacteria & 0.254 & 0.138 & 0.312 \\
\hline Euryarchaeota & 0.051 & 0.260 & 0.952 \\
\hline Fibrobacteres & 0.565 & 0.747 & 0.241 \\
\hline Firmicutes & 0.562 & 0.138 & 0.371 \\
\hline Proteobacteria & 0.259 & 0.006 & 0.776 \\
\hline Spirochaetes & 0.672 & 0.013 & 0.219 \\
\hline
\end{tabular}

In the fecal samples, more than $99 \%$ of the sequences were affiliated to the same nine main phyla compared to those found in the rumen. However, Firmicutes were largely dominant, with more than $55 \%$ of the total sequences overall. Bacteroidetes represented between 27.4 and $34.2 \%$ of the sequences on average (Figure 4).

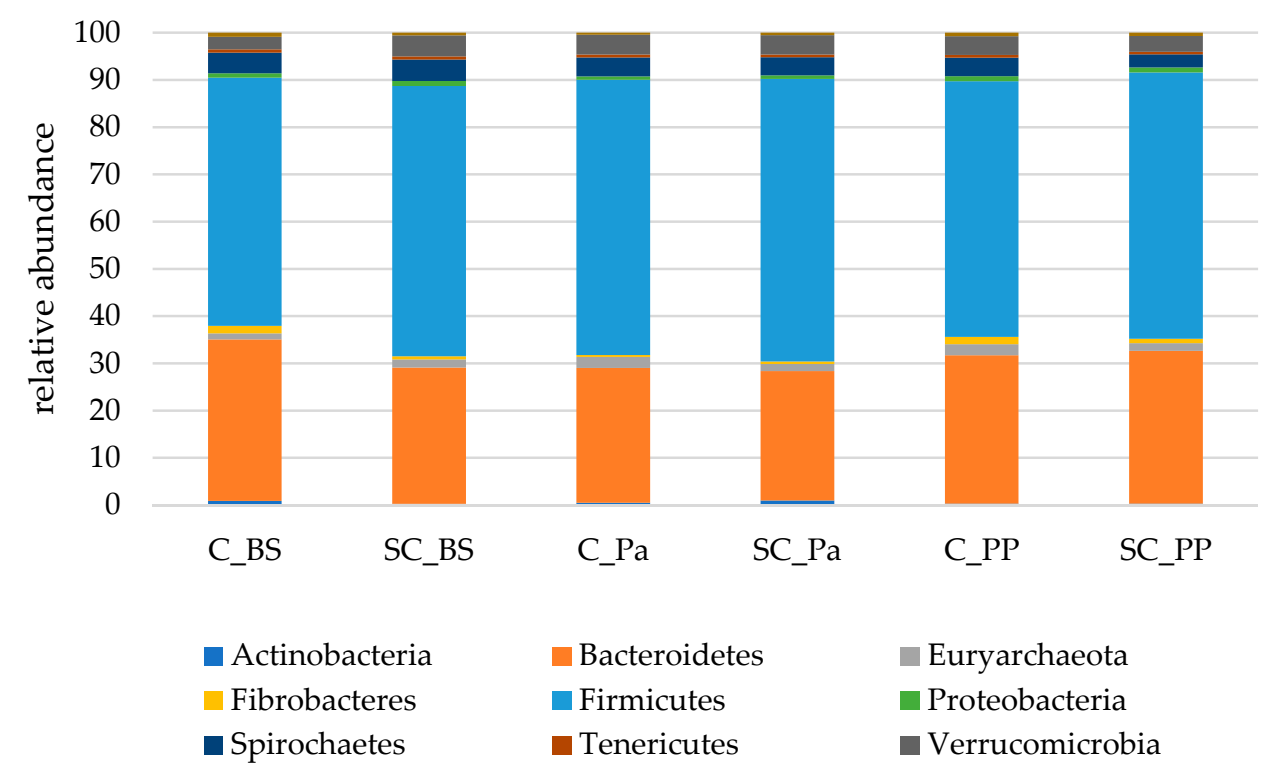

Figure 4. The relative abundances of the main bacterial and archaeal phyla in the fecal samples of both the experimental groups (Control C and Supplemented SC, $n=6$ per group) BS (before supplementation), Pa (close to parturition) and PP (2 weeks postpartum).

In the feces, a different evolution in the relative abundances of Actinobacteria (mainly Coriobacteriaceae and Bifidobacteriaceae families) was observed over the experiment between the groups (Figure S6). In the control group, the relative abundance of Actinobacteria was continuously decreasing from $0.87 \%$ to $0.32 \%$, while there was a higher relative abun- 
dance in the SC group at Pa and PP ( $p=0.015$ and $p=0.009$ for Pa and PP, respectively, according to the Mann-Whitney test on normalized values). Bacteroidetes decreased at $\mathrm{Pa}$ in both groups but increased to higher values at PP in the SC group compared to the control group (Table 6), and this evolution was partly linked to the relative abundance of Prevotellaceae. The relative abundance of Fibrobacteres significantly decreased at $\mathrm{Pa}$, with more drastic variations observed in the control group ( $-76 \%$, from $1.6 \%$ to $0.4 \%$ ) compared to the SC group (-17\%, from $0.7 \%$ to $0.5 \%$ ). An increase in Fibrobacteres was observed in both groups at PP. A time effect was observed for Proteobacteria which were decreasing at $\mathrm{Pa}$ and increasing afterwards.

Table 6. $p$-values associated with the statistical analysis of the relative abundances of the bacterial and archaeal communities in the fecal samples with a linear mixed model.

\begin{tabular}{cccc}
\hline Phylum & Group & Time & G $\times \mathbf{~}$ \\
\hline Bacteroidetes & 0.044 & 0.034 & 0.523 \\
\hline Euryarchaeota & 0.355 & 0.928 & 0.920 \\
\hline Fibrobacteres & 0.066 & 0.0001 & 0.013 \\
\hline Firmicutes & 0.442 & 0.146 & 0.891 \\
\hline Proteobacteria & 0.614 & 0.004 & 0.936 \\
\hline Spirochaetes & 0.241 & 0.414 & 0.495 \\
\hline Tenericutes & 0.914 & 0.357 & 0.953 \\
\hline Verrucomicrobia & 0.183 & 0.453 & 0.712 \\
\hline
\end{tabular}

- Differential analysis of OTUs

A DESeq2 analysis was performed on the $16 \mathrm{~S}$ data at the OTU level. The analysis confirmed a significant difference between the two groups before supplementation.

In the rumen, it should be noted that a sample from one ewe in the Control group was highly enriched in Listeria just before parturition $\left(22 \log _{2}\right.$ fold change $C$ vs. SC at $\mathrm{Pa}$, corresponding to $0.7 \%$ relative abundance), and postpartum, a comparable level of enrichment was found but it was in another ewe (24 $\log _{2}$ fold change $C$ vs. SC at PP, corresponding to $4.0 \%$ relative abundance). Six OTUs were found in higher abundance BS compared to Pa: Ruminobacter in the SC group and Ruminococcaceae, Phocaeicola, Rikenellaceae, and Sphaerocheata in the control group. In the rumen, Listeria was enriched at $\mathrm{Pa}$ in the control group vs. BS, as previously noted. Between Pa and PP, differentially abundant OTUs were only found in the SC group, with an enriched abundance of several Prevotallaceae OTUs at Pa compared to PP.

In the feces, several OTUs were observed in higher abundance in the C or SC groups before supplementation: 3 OTUs in the SC group and 18 OTUs in the control group. Listeria was more represented in the feces of the supplemented group before supplementation than at parturition $\left(8.2 \log _{2}\right.$ fold change BS vs. Pa in the SC group, average of $0.2 \%$ relative abundance). The temporal analysis was thus driven by the differences observed BS. In the feces, 29 OTUs were more represented in the samples collected before supplementation than at $\mathrm{Pa}$, all in the control group. Bifidobacterium and Paeniclostridium were the only 2 OTUs enriched in the SC group at $\mathrm{Pa}\left(4.76\right.$ and $1.98 \mathrm{Log}_{2}$ fold change Pa vs. BS in the SC group, respectively). Fibrobacter related OTU decreased in the control group at $\mathrm{Pa}$, compared to BS. Two weeks postpartum, Bifidobacterium OTU was enriched in both the groups compared to just before parturition (4.97 and $4.84 \log _{2}$ fold change PP vs. Pa in the C and SC groups, respectively) and Fibrobacter related OTU was enriched in the control group. 


\subsubsection{S-DNA Sequencing Results}

- $\quad$ Alpha and beta diversity measures

No significant difference in the alpha diversity indexes was observed over time and between the groups according to the Mann-Whitney test on normalized values (Figure S7, $p>0.05)$. We noticed that at $\mathrm{Pa}$, the Shannon index was very variable among the animals in the control group, compared to other time points and to the SC group. The representation of beta diversity indicates that the ruminal samples from the control and SC groups at Pa clustered distinctly from other samples along the PC1 $(42.4 \%)$ and PC2 $(18.7 \%)$ axis and were also clearly discriminated from each other (Figure 5). No other cluster could be easily observed.

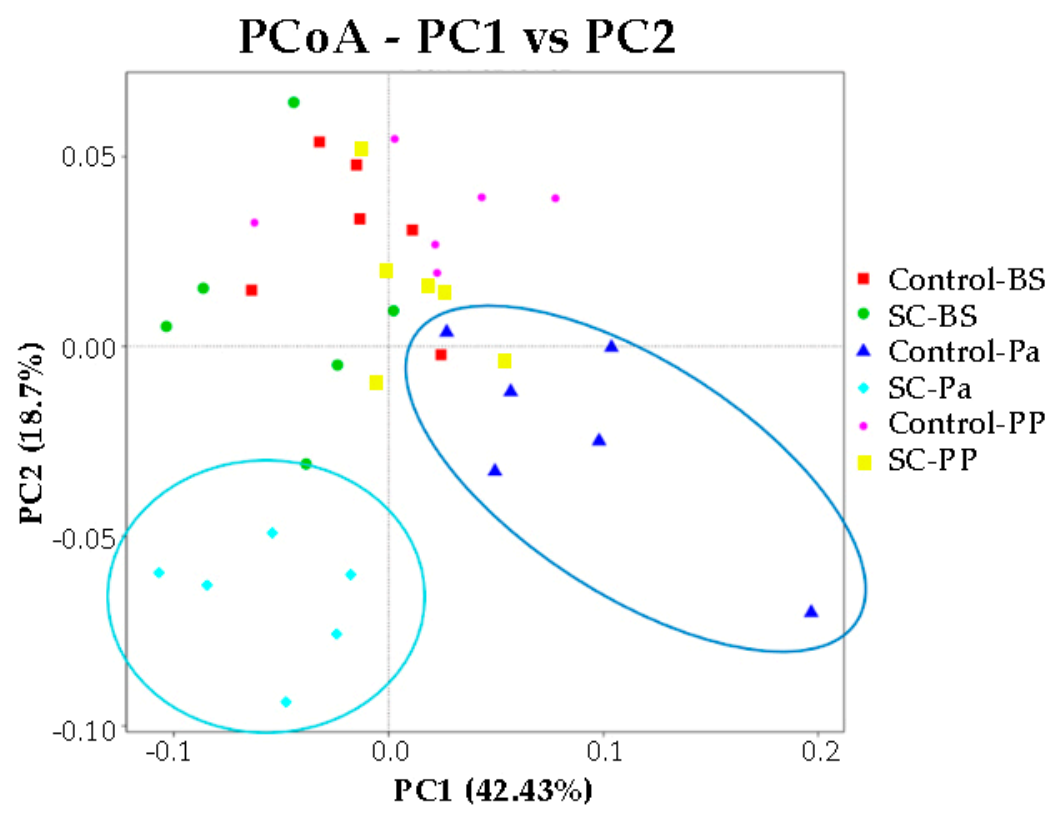

Figure 5. PCoA representation for the eukaryotic and fungal communities in the ruminal samples of the control and SC groups at BS, Pa, and PP.

- Relative abundance of the main taxonomic groups

Eukaryotic communities were studied according to separated functional groups (protozoa, total fungi, anaerobic fungi). The protozoal population was represented by 12 genera (Figure 6). Overall, the genera from the Litostomatea class strongly dominated the eukaryotic populations with a total relative abundance ranging from 99.6 to $99.8 \%$. Entodinium related sequences were the most abundant, followed by Isotricha, Metadinium, and Dasytricha.

Most of the statistical significances for the protozoa population were linked to the time effect (Table 7, Figure S8). It was observed that the relative abundances of Metadinium, Polyplastron, and unidentified Listostomatea significantly decreased at $\mathrm{Pa}$ and then increased afterwards. In contrast, the relative abundances of Dasytricha and Isotricha increased at $\mathrm{Pa}$ then decreased at PP. No significant group effect was observed but some interactions (Time $\times$ Group) were found to be significant. A greater stability in relative abundance was observed for Isotricha and Eudiplodinium in the SC compared to the control group across time. The abundance of Entodinium was stable in the SC group up to Pa then slightly decreased while the opposite trend was observed in the control group (a decrease at $\mathrm{Pa}$ then an increase at PP). No group effect was observed for Diploplastron according to the Mann-Whitney test on normalized values. 


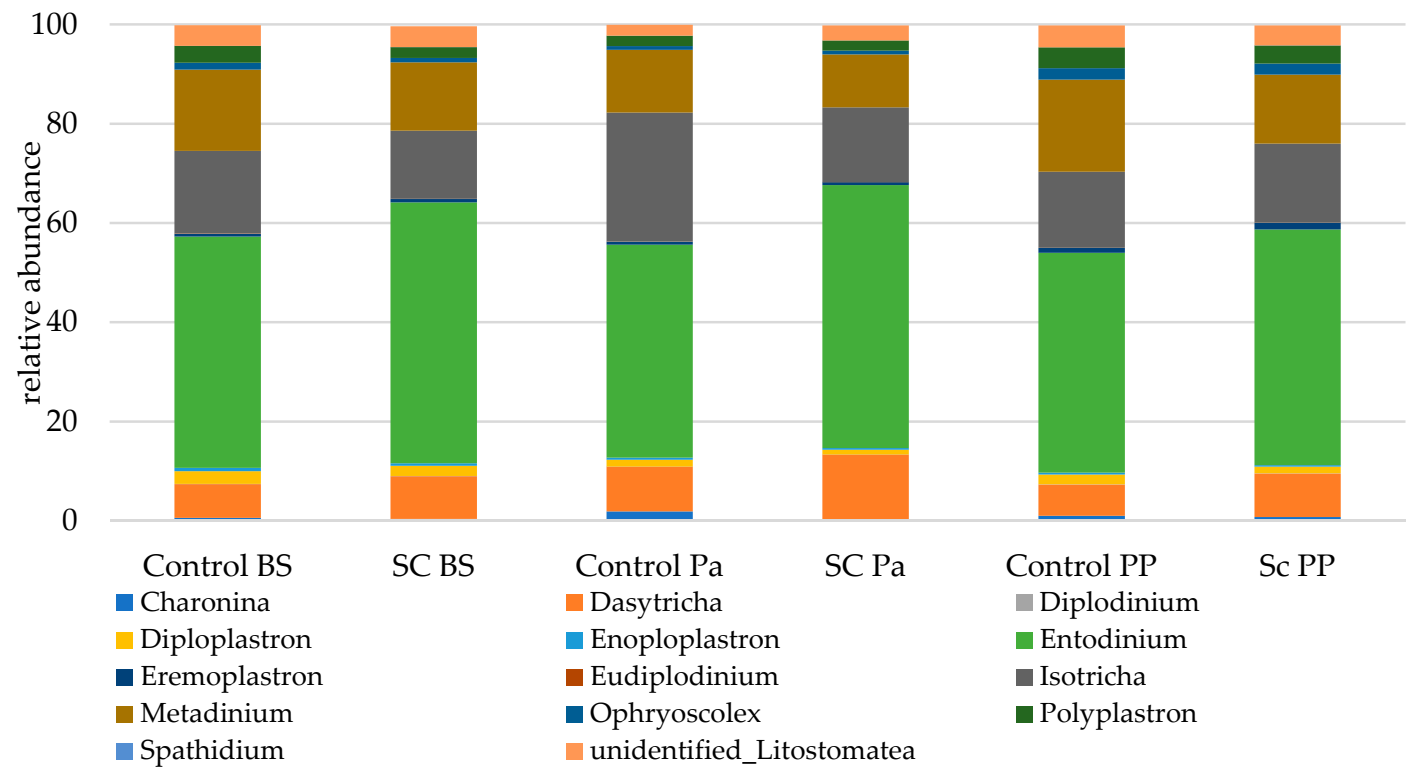

Figure 6. Relative abundance (\% eukaryotic population) of protozoa in the ruminal samples from the control and SC groups $(n=6$ per group) at BS, Pa and PP.

Table 7. $p$-values associated with the statistical analysis of the relative abundances of eukaryote phyla in the ruminal samples with a linear mixed model. Only genera with relative abundance $>2.3 \%$ were kept for statistical analysis, except Eudiplodinium whose abundance was $<2.3 \%$ but which is a functionally important ciliate genus in the rumen.

\begin{tabular}{cccc}
\hline Protozoa & Group & Time & $\mathbf{G} \times \mathbf{T}$ \\
\hline Dasytricha & 0.224 & 0.007 & 0.514 \\
\hline Entodinium & 0.843 & 0.291 & 0.085 \\
\hline Eudiplodinium & 0.871 & 0.899 & 0.041 \\
\hline Isotricha & 0.625 & 0.032 & 0.015 \\
\hline Metadinium & 0.799 & 0.0002 & 0.115 \\
\hline Polyplastron & 0.14 & 0.001 & 0.550 \\
\hline $\begin{array}{c}\text { Unidentified } \\
\text { Litostomatea }\end{array}$ & 0.811 & 0.013 & 0.284 \\
\hline Total Litostomatea & 0.150 & 0.302 & 0.445 \\
\hline
\end{tabular}

Great variations of the three main phyla relative abundances (Neocallimastigomycota, Ascomycota and Basidiomycota) were observed over time (Figure 7). In both groups, parturition was associated with a significant and strong increase in Ascomycota and a concomitant decrease in the relative abundance of Neocallimastigomycota (Table 8, Figure S9). At Pa, Ascomycota were observed in a higher relative abundance in the SC group compared to the control group. This was explained by the significant variations of Saccharomycetales and more precisely by the higher increase in Saccharomyces (from $0.3 \%$ to $5.3 \%$ of fungal abundance) in the SC group compared to the control group at $\mathrm{Pa}$ $(p<0.001$, Mann-Whitney test). The higher relative abundances of Saccharomyces and Saccharomycetales in the SC group remained postpartum $(p<0.05$, Mann-Whitney test) although both groups presented a decrease from Pa to PP. The relative abundances of Basidiomycota varied differently between the groups as it increased at $\mathrm{Pa}$ in the control group and decreased in the SC group. Similar relative abundances were observed PP in both groups. No group effect was observed for Chytridiomycota according to the Mann-Whitney test on normalized values. 


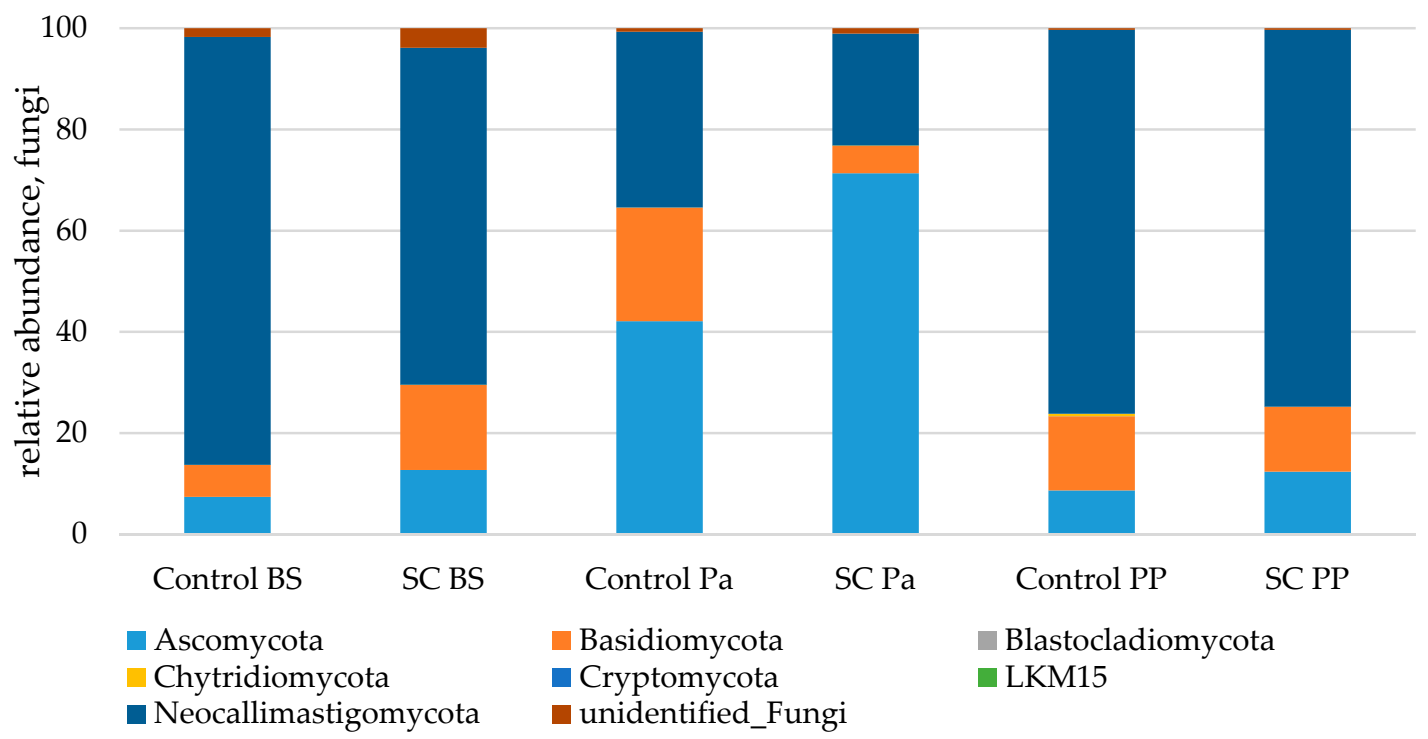

Figure 7. Relative abundance (\%) of fungi in the ruminal samples from the control and SC groups ( $n=6$ per group) at BS, $\mathrm{Pa}$ and PP.

Table 8. $p$-values associated with the statistical analysis of the relative abundances of fungi phyla in the rumen. Only phyla with a relative abundance $>1 \%$ were kept for statistical analysis.

\begin{tabular}{cccc}
\hline Phylum & Group & Time & G $\times$ T \\
\hline Ascomycota & 0.103 & $<0.0001$ & 0.065 \\
\hline Basidiomycota & 0.009 & 0.971 & 0.289 \\
\hline Neocallimastigomycota & 0.229 & $<0.0001$ & 0.528 \\
\hline Unidentified fungi & 0.209 & 0.001 & 0.111 \\
\hline
\end{tabular}

Among Saccharomycetales, a significant interaction of time and group was observed for Pichia ( $p=0.0248)$ which was observed only at the beginning of the trial in the control group and was not retrieved afterwards, while it remained at a low relative abundance in the SC group up to Pa. No effect of the factors and their interaction was observed for Debaryomyces, Candida, and total non-Saccharomyces taxa (linear mixed model or MannWhitney test, data not shown). Anaerobic fungi related sequences were identified as belonging to Orpinomyces, Cyllamyces, and Neocallimastigaceae family members as well as Chytridiales order members (Figure S10A,B).

A significant difference in the total anaerobic fungal population was observed over time. These variations were linked to the Neocallimastigaceae family and Cyllamyces abundances (Table 9). No group effect was observed for unidentified Chytridiales according to the Mann-Whitney test on normalized values.

Table 9. $p$-values associated with the statistical analysis of the relative abundances of anaerobic fungi phyla in the ruminal samples with a linear mixed model.

\begin{tabular}{cccc}
\hline Anaerobic Fungi & Group & Time & G $\times \mathbf{T}$ \\
\hline Cyllamyces & 0.500 & 0.007 & 0.179 \\
\hline Orpinomyces & 0.825 & 0.201 & 0.704 \\
\hline $\begin{array}{c}\text { Unidentified Neocalli- } \\
\text { mastigomycota }\end{array}$ & 0.180 & $<0.0001$ & 0.604 \\
\hline Total & 0.236 & $<0.0001$ & 0.543 \\
\hline
\end{tabular}




\section{- Differential analysis of OTUs}

Compared to the observations on the bacterial microbiota, fewer OTUs (3) were identified as differentially abundant between the SC and C groups. Saccharomyces OTUs were significantly enriched in the SC group compared to the control group at $\mathrm{Pa}$ and $\mathrm{PP}$ but also at BS. Two OTUs belonging to the Agaricomycetes order and Dibaeis genus were highly enriched in the control group at $\mathrm{Pa}$ (25.26 and $24.23 \mathrm{Log}_{2}$ fold change Pa vs. $\mathrm{BS}$, respectively).

Ten OTUs were identified as significantly more represented before the SC supplementation compared to Pa. Lichtheimia and Mucor were the two genera more represented BS in both the SC and C groups. Saccharomyces was found to be significantly enriched also in both groups a few days before parturition with similar $\log _{2}$ fold changes $(-5.59$ in the control groups and -5.73 in the SC groups, representing an increase between BS and Pa in relative abundance from $0.02 \%$ to $0.7 \%$ and from $2.4 \%$ to $53.0 \%$ ). This observation could also be made when comparing the period $\mathrm{Pa}$ and $\mathrm{PP}$, with -6.84 and $-7.07 \log _{2}$ fold changes in the SC and control groups, respectively, indicating a decrease in the relative abundance during this period. From the 19 OTUs differentially observed during the pre-parturition period (comparison BS-Pa), 11 evolved the opposite way during the post-parturition period $(\mathrm{Pa}-\mathrm{PP})$, indicating that these OTUs were coming back to their initial levels.

\subsection{Blood Biomarkers}

\subsubsection{Oxidative Stress Blood Markers}

A decrease in the FRAP was observed for both groups close to parturition (from 0.30 to $0.28 \mathrm{mmol} \mathrm{Fe} e^{2+} / \mathrm{L}$ in the control group and from 0.31 to $0.26 \mathrm{mmol} \mathrm{Fe}^{2+} / \mathrm{L}$ in the SC group, Figure 8A). This antioxidant capacity was significantly lower for the SC group $(p=0.012)$. The GPx activity increased around parturition for both groups. More precisely, a $29 \%$ increase (from 0.82 to $1.06 \mu \mathrm{mol} / \mathrm{min} / \mathrm{mL}$ ) in the GPx activity was measured in the SC group around parturition, however the difference was not significant $(p=0.199)$. Finally, a significant effect of group was observed for MDA $(p=0.003)$. In the control group, MDA increased from 0.14 to $0.21 \mu \mathrm{g} / \mathrm{mg}$ protein from BS to $\mathrm{Pa}$, whereas it decreased in the SC group from 0.20 to $0.18 \mu \mathrm{g} / \mathrm{mg}$ protein.

A

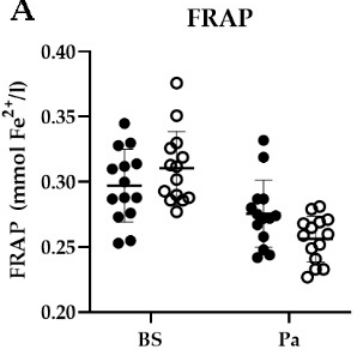

B

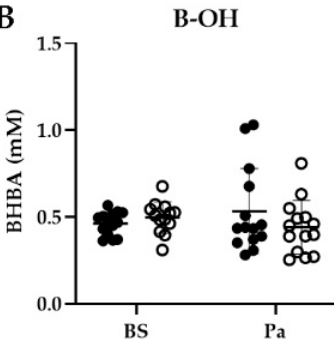

GPx
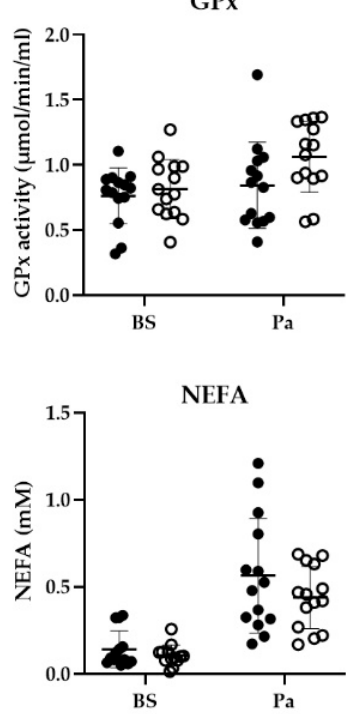

MDA
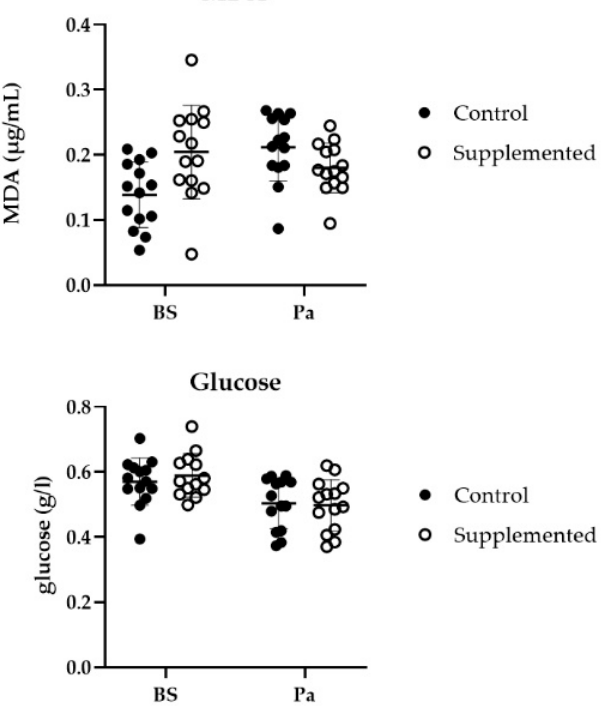

Figure 8. (A) Ferric reducing ability of plasma (FRAP, mmol Fe $\left.{ }^{2+} / \mathrm{L}\right)$, GPx activity ( $\mu \mathrm{mol} / \mathrm{min} / \mathrm{mL}$ ) and plasmatic MDA concentration ( $\mu \mathrm{g} / \mathrm{mg}$ protein); (B) BHBA $(\mathrm{mM})$, NEFA $(\mathrm{mM})$ and glucose $(\mathrm{g} / \mathrm{L})$ in the control (full circle) or the SC (open circle) ewes before supplementation (BS) and around parturition $(\mathrm{Pa})(n=14$ per group). 


\subsubsection{Metabolic Status Blood Markers}

As parturition approached, the NEFA concentration increased in both groups $(+0.42 \mathrm{mM}$ and $+0.34 \mathrm{mM}$ in the control group and the SC group, respectively, Figure $8 \mathrm{~B}$ ) while the blood glucose concentration slightly decreased $(-0.07 \mathrm{~g} / \mathrm{L}$ and $-0.05 \mathrm{~g} / \mathrm{L}$ in the control group and the SC group, respectively). The BHBA variations were different between the two groups as it increased in the control group and decreased in the SC group. However, none of these variations were found to be significantly different $(p>0.05)$.

Liver function was also evaluated through aminotransferases (alanine and aspartate aminotransferases: ALT, AST), gamma-glutamyl transferase $(\gamma-\mathrm{GT})$, and alkaline phosphatase (ALP) activities. No significant difference was found considering the time and group factors or their interaction for the enzymatic activities tested due to quite high intraindividual variations $(p>0.05)$. Different variations were observed for the $\gamma$-GT activity which decreased in the control group but increased in the SC group, but the variation in this latter group was driven by one animal only (the same animal being slightly higher in AST activity).

\subsection{Lambs Birth Weight}

Nine out of 14 ewes from the control group and 12 out of 14 ewes from the SC group gave birth to twin lambs and only these pairs were taken into account for birth weight analysis. The average weight of the lambs born from the control ewes was $3.74 \mathrm{~kg} \pm 0.52$ whereas the average weight of the lambs from the SC group was $4.01 \mathrm{~kg} \pm 0.80$, which represented a $7.2 \%$ increase, although this was not significant $(p>0.05)$. The remaining ewes gave birth to either one single lamb (two ewes from the control group, one for the SC group) or to three lambs (three ewes from the control group, one for the SC group).

\section{Discussion}

While recent data are available on the changes that may occur in the rumen and the fecal microbial abundance, diversity, and taxonomic composition around parturition in dairy cows $[4,6,35]$, and on the beneficial effects which are observed in the case of live yeast supplementation during this risky period [4,7], to our knowledge data on small ruminants are very scarce, in particular on ovines. The peri-parturition period is considered very stressful for the female because many profound changes in hormonal status, physiology, and metabolism occur. Metabolic changes are partly triggered by a change in diet in dairy cows, as high levels of readily fermentable carbohydrates are fed to ensure the nutritional requirements at the start of the lactating phase. Thus, the shifts in the microbiota balance in both the rumen and the lower gut can be, at least in part, explained by the modifications of both the level and the nature of nutrients that are offered to the microorganisms. For instance, in the study of Bach et al. [4], the increase in non-fiber carbohydrates in the diet was between 6 and $7 \mathrm{~kg} /$ day per cow, which obviously put the cows at more risk for ruminal acidosis. Thus, in dairy cows, where the inclusion of a high fermentable concentrate is compulsory to maximize milk production after calving, the impact of the hormonal, physiological, and metabolic stresses can have very negative consequences on the performance and overall health of the animal.

In our study with ewes, the nutritional context was different, as the animals were fed a high forage diet across the peri-parturition period and the level of the rapidly fermentable concentrate was not increased after lambing, because the objective was not to maximize milk production. Therefore, the diet offered at parturition was not particularly at risk for ruminal acidosis, which we indeed did not observe throughout the trial.

\subsection{What Was the Microbial Profile in Gestating Ewes?}

One month before lambing, the composition of the rumen microbiota in the ewes was quite comparable to what has been reported in the literature in adult ovines. Bacteroidetes were dominant $(50-60 \%)$, followed by Firmicutes $(25-30 \%)$, Fibrobacteres $(5-8 \%)$, Euryarchaeota $(2-7 \%)$, Spirochaetes $(2 \%)$, Verrucomicrobia (1-2\%) and Proteobacteria (1-2\%). 
We noticed a quite high abundance of Fibrobacter, which represented around $5-8 \%$ of the total bacterial read by $16 \mathrm{~S}$ sequencing, and around $5 \%$ of the total bacteria quantified by qPCR. The quite high abundance of Fibrobacteres is likely due to the high forage content of the diet. The species F. succinogenes was clearly dominant compared to the other fibrolytic species Ruminococcus flavefaciens and R. albus, which were quantified at much lower levels in our study. These results are in agreement with the data obtained by Mosoni et al. in adult sheep [17]. The qPCR detection of Megasphaera elsdenii, an important lactate utilizer, was very weak whatever the physiological stage, which is in agreement with the fact that the diet was low in readily fermentable sugars which are generally responsible for massive fermentation, lactate accumulation, and can lead to acidosis [36].

Rumen protozoa were quantified at levels which agree with the literature $[37,38]$. The $18 \mathrm{~S}$ sequencing data showed a dominance of the Entodinium genus, which is fully in accordance with previously reported data, with small Entodinomorphs accounting for $95 \%$ of the total ciliate population in sheep [39]. Among the $18 \mathrm{~S}$ sequences attributed to fungi, the typical ruminal anaerobic taxa Neocallimastigomycota was detected at a high relative abundance (more than $65 \%$ ), with assigned sequences to Orpinomyces and Cyllamyces genera. It can be suggested that the high forage diet used in this study promoted this important fibrolytic phylum [40].

\subsection{What Happened to the Digestive Microbiota and Activity of Control Ewes Around Parturition?}

In the rumen, the bacterial diversity was impacted by parturition as indicated by the significant time effect on the richness and the evenness indexes. Some changes in the abundance of certain groups were measured and microbial activity seemed to be impacted as well, as shown by the VFA pattern. Several studies have shown that the rumen microbiota balance altered around parturition in cows, which was, most of the time, tightly linked to a change in diet, with higher levels of readily fermentable carbohydrates. Indeed, DNA sequencing studies on the rumen microbiota have reported a decrease in the fibre-degrading bacterial populations such as the Fibrobacterales and Clostridiales orders, and an increase in Bacteroidales, with a particular increase in the genus Prevotella, after calving [41].

In our study, a significant time effect was observed for Proteobacteria and Spirochaetes in the rumen of the control ewes, with an increase in the relative abundance in those phyla over time. We noticed a numerical decrease in the Fibrobacter succinogenes concentration, measured by qPCR, in the rumen of the control ewes at lambing, compared to one month before parturition. This was corroborated with $16 \mathrm{~S}$ sequencing data which showed an almost $40 \%$ decrease in the relative abundance of the Fibrobacteres phylum, which gathers only one genus, Fibrobacter. This important fibrolytic bacterial species s plays a key role in fiber digestion [42-44]. This species has been reported to be quite sensitive to changes in the ecological conditions of the rumen [45], which might have occurred at parturition. As F. succinogenes represents a high proportion of the total bacteria in the rumen of our ewes and given its high contribution to plant cell wall degradation, even a small decrease in its concentration could impact fiber digestibility. Only a very few OTUs were found to be differentially represented around parturition. A very marked result was the enrichment in Listeria-affiliated sequences in the rumen of the control ewes around parturition. However, this observation was linked to only one individual at $0.7 \%$ at Pa. Regarding eukaryotic communities, we observed a $0.4 \log _{10}$ decrease in the ciliate protozoa concentration after parturition only ( $p=0.062$ with the Wilcoxon test). Variations across the periods in the protozoa and fungi taxonomic composition were also observed: a significant decrease in the relative abundance of anaerobic fungi (Neocallimastigomycota and Cyllamyces) was measured around parturition, while Ascomycota (Saccharomyces) increased. Variations in relative abundances were also observed in the protozoa population. Overall, our results suggest that around parturition, changes in the ecological conditions in the rumen could occur and become less favorable to the stability of the eukaryotic community. 
In the control ewes, a numerical decrease in the total VFA concentration (about $-9 \%$ ), mainly reflected by a decrease in acetate (about $-8 \%$ ), was observed a few days before parturition, followed by an important increase postpartum (about $+29 \%$ ). This may reflect an instability of microbial fermentations.

In the feces of the control group, a strong decrease in bacteria alpha diversity has been noticed at lambing followed by an increase after parturition. Bach et al. measured a decrease in the bacteria diversity in the colon of cows a few days after calving, lasting even 3 weeks postpartum [4]. This difference could be, at least in part, explained by the diet composition in the two studies, as in the Bach et al. study, readily fermentable carbohydrates were increased in the post calving diet, which was probably more prone to an increased risk for lower gut dysbiosis that the one used in our study. Fecal 16S sequencing data indicated that the relative abundance of the Bacteroidetes phylum decreased close to parturition and then increased postpartum. Several members of this phylum are reported to be carbohydrate degraders, so its decrease may suggest a lower activity towards easily digestible fiber in the hindgut. Contrary to what was observed in the rumen at $\mathrm{Pa}$, the relative abundance of Proteobacteria was shown to decrease.

A differential analysis of OTUs showed a significant increase in two OTUs affiliated to the Ruminococcaceae family at parturition. This family is functionally very diverse. As some Ruminococcus species can compete with Fibrobacter succinogenes for cellulose [46], the decrease in this latter genus may open ecological niches for other Ruminococcaceae family members. A differential analysis showed that the relative abundance of one OTU affiliated to the Fibrobacteres phylum decreased between BS and Pa by almost $80 \%$. After parturition, this OTU was enriched, suggesting the quite high instability of the environment. As these results were not confirmed by qPCR, it is possible that this OTU corresponds to Fibrobacter intestinalis, which is the second species described for the Fibrobacter genus [47] and the main Fibrobacter species in the intestine [48], and which was not targeted by our qPCR primers. In addition, a substantial number of OTUs appeared to be impacted close to parturition, with the majority being underrepresented when compared to their relative abundance at the start of the trial (BS). This may again reflect some instability of the fecal communities in the control ewes. OTUs related to Agaricomycetes and Dibaeis fungi were identified as differential in our data (increased at $\mathrm{Pa}$ ). These sequences probably come from some contamination from the bedding material, which may have been ingested by the animals, as at parturition the bedding could be wetter and more prone to fungal growth.

It should be noticed that high inter-individual variations were observed in the rumen while the relative abundances observed in the feces were more consistent among the animals, allowing several taxa to reach significance more easily. It can be hypothesized that as the rumen is the first digestive compartment of the digestive tract, the microbial population is more prone to be impacted by external stimuli. Parturition is known to reduce rumination behavior and thus is expected to impact the flow rate of feed, the fermentative activities, and the microbial profile of the rumen.

\subsection{What Was the Impact of Parturition on Oxidative and Metabolic Status of the Control Ewes?}

The transition period is associated with several physiological stresses. The metabolism of a late gestating ruminant is characterized by a decreased DMI and a decreased amount of glucose available in the blood, creating a negative energy balance (NEB). As already observed, during the ewes' transition period [49], blood glucose decreased in our study as the animal reached parturition, while the NEFA concentration increased in agreement with Castillo et al. [50] in their study on dairy cows. Other liver biomarkers were not affected in our study, reflecting the correct adaptation of the gestating animal to the diet.

The transition period is also associated with an unbalanced pro-oxidant/antioxidant system producing an excess of reactive oxygen species (ROS) while the antioxidant capacity is decreased [51]. Malondialdehyde (MDA) is a marker of lipid peroxidation. MDA variations observed in the control ewes during the last month of gestation (between BS and $\mathrm{Pa}$ ) were in line with the literature on pregnant ewes [52] and dairy cows [50], but not 
with other studies on ovines [49,51]. These differences are likely partly due to different methodological approaches, as in our case we precisely measured the MDA concentration using an adapted HPLC technique, whereas in the last two cited studies, MDA was only estimated through a thiobarbituric acid-reactive substances (TBARs) measurement. Only a little information exists on gestating ewes, but in dairy cows, metabolic and oxidative stresses in transition are expected to be even higher as they produce high milk quantities, thus threatening the physiological homeostasis [53]. The enzyme glutathione peroxidase (GPx) is recognized to limit lipid peroxidation. Our results showed a slight numerical increase in the GPx activity, but variations of this activity have been reported to occur depending on the physiology of the species, and even on breeds within the same species $[52,53]$.

\subsection{What Were the Effects of S. Cerevisiae I-1077 Supplementation around Parturition?}

As expected, the Saccharomyces concentration increased in the rumen samples of the SC group only during the S. cerevisiae I-1077 (SC) supplementation period. Q-PCR data also indicated a similar increase of Saccharomyces at $\mathrm{Pa}$ in the feces of the supplemented ewes, which suggested that the SC cells were able to reach the hindgut segments during their digestive transit, which confirms earlier results [54]. The effective presence of the SC additive is important to support its action in the different compartments of the gastrointestinal tract [55].

The SC supplementation induced some changes in the diversity and the dynamics of microbiota and fermentation, leading overall to a stabilization of the digestive conditions.

In more detail, the negative impact of parturition on Fibrobacter that we saw in the control group was alleviated in the SC supplemented animals in the rumen. Although our data could not reach significance, probably because of the low number of animals and inter-individual variability, we could observe different evolutions in the F. succinogenes concentrations between the two groups, and a stronger decrease in the relative abundance of the Fibrobacteres phylum in the control group close to parturition, which makes our hypothesis tangible. This species has shown to be quite responsive to the live yeast strain used in the present study $[12,45,56]$. S. cerevisiae I-1077 active cells may improve the rumen environment by scavenging oxygen and providing vitamins or cofactors that may help the bacterial species to maintain [12].

In the rumen of supplemented animals, a lower relative abundance of Euryarchaeota and Verrucomicrobia phyla were observed close to parturition and postpartum, respectively, compared to the control group. Euryarchaeota are methanogens in the rumen and members of the Verrucomicrobia phylum have been reported to release $\mathrm{H}_{2}$ from complex polysaccharide degradation [57]. The Verrucomicrobia family RFP12 was found to be prevalent in the rumen of high methane yielding animals [58]. In a recent trial in beef cattle fed a high forage diet [59], the same strain of S. cerevisiae that we used also had an impact on Verrucomicrobia, with a decrease in the relative abundance of this phylum. However, further work is needed, such as methane and $\mathrm{H}_{2}$ quantifications, to explain the effects of SC supplementation on these taxa.

Moreover, we noticed from our $18 \mathrm{~S}$ sequence analysis that protozoa taxonomic ruminal composition was more stable around parturition in the SC group (Entodinium, Isotricha). In addition, Pichia was maintained in the rumen of the SC ewes at Pa while it disappeared in the control group. It would be of interest to promote this yeast genus, as it has been recently reported that a microbial feed additive containing a strain of Pichia could improve the milk yield in dairy cows [60]. At Pa, the relative abundance of Ascomycota was clearly increased in the SC supplemented ewes, as expected. The beta diversity PCoA plots showed that the eukaryotic communities were different in both groups.

We noticed a more stable total VFA concentration across the periods in the SC group, whereas decreased levels of VFA were measured at parturition in the control group, mainly driven by acetate concentrations. These data suggest a beneficial effect of the live yeast supplementation on microbial activity in the rumen. 
Another interesting result was the stabilization of the bacterial fecal diversity throughout the study, as indicated by the significant differences between the groups. Indeed, the supplemented animals presented stable diversity indexes over time, while a strong decrease in the alpha diversity indexes was observed in the control group at Pa. Such a sharp decrease in diversity in the hindgut may increase the risk for opportunistic pathogens to find a free ecological niche in which to settle and trigger disease [61]. Moreover, the decrease in the Bacteroidetes phylum which was observed at parturition in the control group was alleviated in the feces of the SC supplemented animals. The same observation could be raised for the Fibrobacteres phylum which was kept very stable across the whole experimental period in the SC supplemented ewes, as observed in the rumen. A stable community is generally less prone to the setup of a dysbiotic state.

Supplementation strategies to reduce oxidative stress may reduce the economic losses associated with health disorders observed during the transition period [62]. Our data suggest that supplementation by SC during late gestation alleviated oxidative stress in the ewes. Although not significant, the activity of the antioxidant enzyme GPx showed an increase of $+29 \%$ just before parturition in the SC group, while the increase was less important $(+6 \%)$ in the control group. Moreover, the MDA level was shown to decrease in the SC group, an opposite variation to what was observed in the control animals. SC supplementation seemed to have induced pro/antioxidants production modifications. Taken together, these data are promising, but more research is needed to better understand and elucidate the molecular mechanisms by which live probiotics interact with antioxidant and immunological mechanisms. In dairy cows around calving, this live yeast has been able to modulate the inflammatory response and improve the barrier function of the rumen wall [7], with concomitant changes in the rumen microbiota diversity and composition [4] It has been reported that rumen microbial fractions, such as bacterial LPS, would play a role in proinflammatory and prooxidative responses [8], and in periparturient dairy cattle, the concentration of lactic acid isoforms (a ruminal activity biomarker) has been correlated with the oxidant status [63]. It can thus be hypothesized that the SC effect at the rumen microbiota level could have a beneficial impact on oxidative stress. Moreover, the yeast cellular content in B vitamins could also play a role in this effect as some of these vitamins are precursors of important coenzymes involved in oxidation processes. Although we measured a higher decrease in the FRAP level at $\mathrm{Pa}$ in the supplemented animals, it must be reminded that the FRAP reflects only partially the antioxidant capacity as it cannot detect compounds that act by radical quenching (hydrogen transfer), particularly thiols (as glutathione), and some proteins involved in the antioxidant status of the animal [64].

Very few papers address the effect of probiotics on oxidative stress in ruminants, and even less information is available on the effect of such additives on the oxidative status of gestating ruminants. In a recent published work [65], the effect of a live yeast product was investigated in relation to oxidative stress in periparturient ewes with different impacts on the investigated parameters, but the measurements were performed 3 to 6 weeks postpartum, which may be already late regarding oxidative stress. Furthermore, the yeast strain could also be an important factor driving the effects on the oxidative status. Taken together, these data are promising but more research is needed to better understand and elucidate the molecular mechanisms by which live probiotics interact with antioxidant mechanisms.

Although not significant, one observation was a $7.2 \%$ higher birth weight on average for the lambs born from SC-supplemented ewes, compared to the controls, which would suggest a beneficial side effect of SC supplementation. We could thus hypothesize that a live yeast supply to late gestating ewes would promote nutrient transfer for fetal growth through a better-balanced digestive function and an improved oxidative status. It is known that the nutritional status of gestating dams does impact the weight of the offspring at birth, which is associated with their vigor, autonomy, and further survival capacity [66]. In particular, late-pregnancy undernutrition was associated with a significant decrease in lamb birth weight [67]. The importance of adequate maternal nutrition and the prevention of oxidative stress has been stretched, especially for ewes bearing multiple fetuses [68]. Fur- 
ther research is needed to confirm this benefit, by measuring the specific parameters linked to the nutritional status of the dams and to the vigor and activity of newborn offspring.

\section{Conclusions}

Overall, this study shows that the peripartum period can be a risk for digestive microbial balance and oxidative status, even in the absence of any dietary challenge. Indeed, we observed a reduced gastro-intestinal bacterial diversity and a decrease in an important plant cell wall polysaccharide-degrading bacteria and fungi due to parturition, as well as an instability in ruminal fermentative activity, which suggested that digestive homeostasis was disrupted, and we measured an increased level of oxidative stress in ewes. We showed that the supplementation of ewes during late gestation with S. cerevisiae I-1077 can help to maintain the key microbial communities involved in digestive efficiency and can stabilize the digestive balance throughout the gastrointestinal tract. A higher antioxidant capacity and a significant lower lipid peroxidation were also observed. In conclusion, our data suggest that live yeast prevented a transient imbalance in the homeostasis of the organism and helped the animals to cope with the stress of parturition.

Supplementary Materials: The following are available online at https://www.mdpi.com/article/10 $.3390 /$ jof7060447/s1, Figure S1: Y diff values at BS, Pa and PP (Mean \pm SD) for total VFA, Acetate, Propionate, Butyrate, Valerate and Caproate (delta $\mathrm{mM})$ in the control or the SC groups $(n=6)$ in the rumen. Multiple comparisons with Sidak's correction are indicated in the figure only for fixed factors time or group with $\# p<0.1,{ }^{*} p<0.05,{ }^{* *} p<0.01$ and ${ }^{* * *} p<0.0001$. Figure S2: $Y_{\text {diff }}$ values at BS, Pa and PP (Mean \pm SD) for S. cerevisiae, total bacteria, R. flavefaciens, Prevotella and R. albus (delta $\log _{10}$ copies/g) in the control or the SC groups $(n=6)$ in the rumen. Multiple comparisons with Sidak's correction are indicated in the figure only for fixed factors time or group with \# $p<0.1$, ${ }^{*} p<0.05,{ }^{* *} p<0.01$ and ${ }^{* *} p<0.0001$. Figure S3: $Y_{\text {diff }}$ values at BS, Pa and PP (Mean \pm SD) for S. cerevisiae (delta $\log _{10}$ copies/g) in the control or the SC groups $(n=6)$ in the feces. Multiple comparisons with Sidak's correction are indicated in the figure only for fixed factors time or group with $\# p<0.1,{ }^{*} p<0.05,{ }^{* *} p<0.01$ and ${ }^{* * *} p<0.0001$. Figure S4: Alpha diversity measures for the bacterial and archaeal communities in (A) ruminal samples and (B) fecal samples. BS = before supplementation of SC, $\mathrm{Pa}=$ close to parturition, $\mathrm{PP}=2$ weeks postpartum. Figure S5: $\mathrm{Y}_{\text {diff }}$ values at BS, Pa and PP (Mean \pm SD) for Actinobacteria, Bacteroidetes, Euryarchaeota, Proteobacteria, Spirochaetes and Verrucomicrobia (delta \%) in the control or the SC groups $(n=6)$ in the rumen. Multiple comparisons with Sidak's correction are indicated in the figure only for fixed factors time or group with $\# p<0.1,{ }^{*} p<0.05,{ }^{* *} p<0.01$ and ${ }^{* *} p<0.0001$. Figure S6: $\mathrm{Y}_{\text {diff }}$ values at BS, Pa and PP (Mean \pm SD) for Actinobacteria, Bacteroidetes, Fibrobacteres and Proteobacteria (delta \%) in the control or the SC groups $(n=6)$ in the feces. Multiple comparisons with Sidak's correction are indicated in the figure only for fixed factors time or group with $\# p<0.1{ }^{*} p<0.05,{ }^{* *} p<0.01$ and ${ }^{* * *} p<0.0001$. Figure S7: Alpha diversity measures for eukaryotic communities in the rumen samples. $\mathrm{BS}=$ before supplementation of $\mathrm{SC}, \mathrm{Pa}=$ close to parturition, $\mathrm{PP}=2$ weeks postpartum. Figure S8: $\mathrm{Y}_{\text {diff }}$ values at BS, Pa and PP (Mean \pm SD) for Dasytricha, Entodinium, Eudiplodinium, Isotricha, Metadinium, Polyplastron and unidentified Litostomatea (delta \%) in the control or the SC groups $(n=6)$ in rumen. Multiple comparisons with Sidak's correction are indicated in the figure only for fixed factors time or group with $\# p<0.1{ }^{*} p<0.05,{ }^{* *} p<0.01$ and ${ }^{* * *} p<0.0001$. Figure S9: $\mathrm{Y}_{\text {diff }}$ values at BS, Pa and PP (Mean \pm SD) for Ascomycota, basidiomycota, Neocallimastigomycota and unidentified fungi (delta \%) in the control or the SC groups $(n=6)$ in the rumen. Multiple comparisons with Sidak's correction are indicated in the figure only for fixed factors time or group with $\# p<0.1{ }^{*} p<0.05,{ }^{* *} p<0.01$ and ${ }^{* * *} p<0.0001$. Figure S10: A: Relative abundance (\% of total fungal population relative abundance) of anaerobic fungi observed in the ruminal samples of the control and the SC groups at BS, Pa and PP. B: $Y_{\text {diff }}$ values at BS, Pa and PP (Mean \pm SD) for Cyllamyces, unidentified Neocallimastigomycota and total anaerobic fungi (delta \%) in the control or the SC groups $(n=6)$ in the rumen. Multiple comparisons with Sidak's correction are indicated in the figure only for fixed factors time or group with $\# p<0.1{ }^{*} p<0.05,{ }^{* *} p<0.01$ and ${ }^{* * *} p<0.0001$. Table S1: Composition of the commercial concentrate, Table S2: Nutritional composition of the diet offered to the ewes, Table S3: qPCR targets and primers, Table S4: rDNA region and primers used for 
Illumina sequencing, Table S5: Q-PCR results for the targeted microbial groups or species in the fecal samples. References $[69,70]$ are cited in Table S3.

Author Contributions: Conceptualization, F.C.-D. and E.F.; methodology, F.C.-D., E.F., L.D., Y.L., M.B., D.E.; software, L.D., F.C.-D., P.R.; validation, L.D., F.C.-D., E.F.; formal analysis, L.D., F.C.-D., Y.L., D.E., A.T.; investigation, L.D., F.C.-D., E.F.; data curation, L.D., P.R.; writing-original draft preparation, L.D., F.C.-D.; writing-review and editing, E.F., M.B., D.D., A.T., P.R., D.E.; supervision, F.C.-D.; project administration, F.C.-D., E.F.; funding acquisition, F.C.-D., E.F. All authors have read and agreed to the published version of the manuscript.

Funding: This research was partially funded by Lallemand SAS.

Institutional Review Board Statement: Procedures on animals were carried out in accordance with the guidelines for animal research of the French Ministry of Agriculture and all other applicable national and European guidelines and regulations for experimentation with animals (see https: / / www.legifrance.gouv.fr/loda/id/JORFTEXT000027038013/ for details, accessed on 3 June 2021). The protocol was favorably evaluated by the Regional Ethics Committee for Animal Experimentation C2EA-02 and the French Research Ministry authorized its implementation with the reference number 14981-2018050417167566V3.

Data Availability Statement: Sequencing data are available in the BioProject SRA database (https: / / www.ncbi.nlm.nih.gov/sra /, accessed on 3 June 2021) as PRJNA713537.

Acknowledgments: The authors would like to thank Catherine Dhainaut and Raphaele Gresse from UMR MEDIS and Martine Tourret and Dominique Graviou from UMR Herbivores for their skilled technical assistance, Aline Cercy, Loic Gaillard, Bruno Viallard and Pierre Chirent from UE Herbipôle for their very valuable help in the animal experiment, Anne de la Foye from UMR Herbivores for her advice in the statistical analysis, and Eric Chevaux, Emmanuelle Apper, and Clothilde Villot from Lallemand SAS for valuable discussions on the results of this study.

Conflicts of Interest: LD, YL and FCD are employees of Lallemand SAS.

\section{References}

1. Abuelo, A.; Hernández, J.; Benedito, J.L.; Castillo, C. Redox Biology in Transition Periods of Dairy Cattle: Role in the Health of Periparturient and Neonatal Animals. Antioxidants 2019, 8, 20. [CrossRef] [PubMed]

2. Hernandez-Castellano, L.; Almeida, A.; Castro, N.; Arguello, A. The Colostrum Proteome, Ruminant Nutrition and Immunity: A Review. Curr. Protein Pept. Sci. 2014, 15, 64-74. [CrossRef] [PubMed]

3. Yeoman, C.J.; Ishaq, S.L.; Bichi, E.; Olivo, S.K.; Lowe, J.; Aldridge, B.M. Biogeographical Differences in the Influence of Maternal Microbial Sources on the Early Successional Development of the Bovine Neonatal Gastrointestinal Tract. Sci. Rep. 2018, 8, 3197. [CrossRef] [PubMed]

4. Bach, A.; López-García, A.; González-Recio, O.; Elcoso, G.; Fàbregas, F.; Chaucheyras-Durand, F.; Castex, M. Changes in the Rumen and Colon Microbiota and Effects of Live Yeast Dietary Supplementation during the Transition from the Dry Period to Lactation of Dairy Cows. J. Dairy Sci. 2019, 102, 6180-6198. [CrossRef] [PubMed]

5. Pitta, D.W.; Indugu, N.; Baker, L.; Vecchiarelli, B.; Attwood, G. Symposium Review: Understanding Diet-Microbe Interactions to Enhance Productivity of Dairy Cows. J. Dairy Sci. 2018. [CrossRef] [PubMed]

6. Zhu, Z.; Kristensen, L.; Difford, G.F.; Poulsen, M.; Noel, S.J.; Abu Al-Soud, W.; Sørensen, S.J.; Lassen, J.; Løvendahl, P.; Højberg, O. Changes in Rumen Bacterial and Archaeal Communities over the Transition Period in Primiparous Holstein Dairy Cows. J. Dairy Sci. 2018, 101, 9847-9862. [CrossRef] [PubMed]

7. Bach, A.; Guasch, I.; Elcoso, G.; Chaucheyras-Durand, F.; Castex, M.; Fàbregas, F.; Garcia-Fruitos, E.; Aris, A. Changes in Gene Expression in the Rumen and Colon Epithelia during the Dry Period through Lactation of Dairy Cows and Effects of Live Yeast Supplementation. J. Dairy Sci. 2018, 101, 2631-2640. [CrossRef] [PubMed]

8. Abaker, J.A.; Xu, T.L.; Jin, D.; Chang, G.J.; Zhang, K.; Shen, X.Z. Lipopolysaccharide Derived from the Digestive Tract Provokes Oxidative Stress in the Liver of Dairy Cows Fed a High-Grain Diet. J. Dairy Sci. 2017, 100, 666-678. [CrossRef] [PubMed]

9. Golder, H.M.; Lean, I.J.; Rabiee, A.R.; King, R.; Celi, P. Effects of Grain, Fructose, and Histidine Feeding on Endotoxin and Oxidative Stress Measures in Dairy Heifers. J. Dairy Sci. 2013, 96, 7881-7891. [CrossRef] [PubMed]

10. Hu, F.; Xue, Y.; Guo, C.; Liu, J.; Mao, S. The Response of Ruminal Fermentation, Epithelium-Associated Microbiota, and Epithelial Barrier Function to Severe Feed Restriction in Pregnant Ewes. J. Anim. Sci. 2018, 96, 4293-4305. [CrossRef]

11. Abuelo, A.; Hernández, J.; Benedito, J.L.; Castillo, C. The Importance of the Oxidative Status of Dairy Cattle in the Periparturient Period: Revisiting Antioxidant Supplementation. J. Anim. Physiol. Anim. Nutr. 2015, 99, 1003-1016. [CrossRef]

12. Chaucheyras-Durand, F.; Walker, N.D.; Bach, A. Effects of Active Dry Yeasts on the Rumen Microbial Ecosystem: Past, Present and Future. Anim. Feed Sci. Technol. 2008, 145, 5-26. [CrossRef] 
13. Jiang, Y.; Ogunade, I.M.; Qi, S.; Hackmann, T.J.; Staples, C.R.; Adesogan, A.T. Effects of the Dose and Viability of Saccharomyces Cerevisiae. 1. Diversity of Ruminal Microbes as Analyzed by Illumina MiSeq Sequencing and Quantitative PCR. J. Dairy Sci. 2017, 100, 325-342. [CrossRef] [PubMed]

14. Terré, M.; Maynou, G.; Bach, A.; Gauthier, M. Effect of Saccharomyces Cerevisiae CNCM I-1077 Supplementation on Performance and Rumen Microbiota of Dairy Calves. Prof. Anim. Sci. 2015, 31, 153-158. [CrossRef]

15. Guo, Y.; Xu, X.; Zou, Y.; Yang, Z.; Li, S.; Cao, Z. Changes in Feed Intake, Nutrient Digestion, Plasma Metabolites, and Oxidative Stress Parameters in Dairy Cows with Subacute Ruminal Acidosis and Its Regulation with Pelleted Beet Pulp. J. Anim. Sci. Biotechnol. 2013, 4, 31. [CrossRef] [PubMed]

16. Villot, C.; Meunier, B.; Bodin, J.; Martin, C.; Silberberg, M. Relative Reticulo-Rumen PH Indicators for Subacute Ruminal Acidosis Detection in Dairy Cows. Anim. Int. J. Anim. Biosci. 2018, 12, 481-490. [CrossRef] [PubMed]

17. Mosoni, P.; Chaucheyras-Durand, F.; Béra-Maillet, C.; Forano, E. Quantification by Real-Time PCR of Cellulolytic Bacteria in the Rumen of Sheep after Supplementation of a Forage Diet with Readily Fermentable Carbohydrates: Effect of a Yeast Additive. J. Appl. Microbiol. 2007, 103, 2676-2685. [CrossRef]

18. Bayat, A.R.; Kairenius, P.; Stefański, T.; Leskinen, H.; Comtet-Marre, S.; Forano, E.; Chaucheyras-Durand, F.; Shingfield, K.J. Effect of Camelina Oil or Live Yeasts (Saccharomyces Cerevisiae) on Ruminal Methane Production, Rumen Fermentation, and Milk Fatty Acid Composition in Lactating Cows Fed Grass Silage Diets. J. Dairy Sci. 2015, 98, 3166-3181. [CrossRef]

19. Magoč, T.; Salzberg, S.L. FLASH: Fast Length Adjustment of Short Reads to Improve Genome Assemblies. Bioinforma. Oxf. Engl. 2011, 27, 2957-2963. [CrossRef] [PubMed]

20. Bokulich, N.A.; Subramanian, S.; Faith, J.J.; Gevers, D.; Gordon, J.I.; Knight, R.; Mills, D.A.; Caporaso, J.G. Quality-Filtering Vastly Improves Diversity Estimates from Illumina Amplicon Sequencing. Nat. Methods 2013, 10, 57-59. [CrossRef] [PubMed]

21. Caporaso, J.G.; Kuczynski, J.; Stombaugh, J.; Bittinger, K.; Bushman, F.D.; Costello, E.K.; Fierer, N.; Peña, A.G.; Goodrich, J.K.; Gordon, J.I.; et al. QIIME Allows Analysis of High-Throughput Community Sequencing Data. Nat. Methods 2010, 7, 335-336. [CrossRef] [PubMed]

22. Edgar, R.C.; Haas, B.J.; Clemente, J.C.; Quince, C.; Knight, R. UCHIME Improves Sensitivity and Speed of Chimera Detection. Bioinformatics 2011, 27, 2194-2200. [CrossRef] [PubMed]

23. Edgar, R.C. UPARSE: Highly Accurate OTU Sequences from Microbial Amplicon Reads. Nat. Methods 2013, 10, 996-998. [CrossRef]

24. Haas, B.J.; Gevers, D.; Earl, A.M.; Feldgarden, M.; Ward, D.V.; Giannoukos, G.; Ciulla, D.; Tabbaa, D.; Highlander, S.K.; Sodergren, E.; et al. Chimeric 16S RRNA Sequence Formation and Detection in Sanger and 454-Pyrosequenced PCR Amplicons. Genome Res. 2011, 21, 494-504. [CrossRef] [PubMed]

25. Wang, Q.; Garrity, G.M.; Tiedje, J.M.; Cole, J.R. Naïve Bayesian Classifier for Rapid Assignment of RRNA Sequences into the New Bacterial Taxonomy. Appl. Environ. Microbiol. 2007, 73, 5261-5267. [CrossRef] [PubMed]

26. Quast, C.; Pruesse, E.; Yilmaz, P.; Gerken, J.; Schweer, T.; Yarza, P.; Peplies, J.; Glöckner, F.O. The SILVA Ribosomal RNA Gene Database Project: Improved Data Processing and Web-Based Tools. Nucleic Acids Res. 2013, 41, D590-D596. [CrossRef] [PubMed]

27. McMurdie, P.J.; Holmes, S. Phyloseq: An R Package for Reproducible Interactive Analysis and Graphics of Microbiome Census Data. PLoS ONE 2013, 8, e61217. [CrossRef] [PubMed]

28. Lahti, L.; Shetty, S. Utilities for Microbiome Analysis; Release 3.12; Microbiome R Package; Bioconductor. 2012. Available online: https://bioconductor.org/packages/release/bioc/html/microbiome.html (accessed on 6 March 2021).

29. Love, M.I.; Huber, W.; Anders, S. Moderated Estimation of Fold Change and Dispersion for RNA-Seq Data with DESeq2. Genome Biol. 2014, 15, 550. [CrossRef] [PubMed]

30. Benzie, I.; Strain, J. The Ferric Reducing Ability of Plasma (FRAP) as a Measure of "Antioxidant Power": The FRAP Assay. Anal. Biochem. 1996. [CrossRef]

31. Agergaard, N.; Jensen, P.T. Procedure for Blood Glutathione Peroxidase Determination in Cattle and Swine. Acta Vet. Scand. 1982, 23, 515-527. [CrossRef] [PubMed]

32. Delosière, M.; Thomas, A.; Terlouw, C.; Durand, D. Plasma Indicators of Bovine Health: Impacts of Diet Supplementations and Pre-Slaughter Stress. Data Brief 2018, 21, 2496-2503. [CrossRef]

33. Agarwal, R.; Chase, S.D. Rapid, Fluorimetric-Liquid Chromatographic Determination of Malondialdehyde in Biological Samples. J. Chromatogr. B 2002, 775, 121-126. [CrossRef]

34. Van Breukelen, G.J.P. ANCOVA versus Change from Baseline: More Power in Randomized Studies, More Bias in Nonrandomized Studies [Corrected]. J. Clin. Epidemiol. 2006, 59, 920-925. [CrossRef] [PubMed]

35. Derakhshani, H.; Tun, H.M.; Cardoso, F.C.; Plaizier, J.C.; Khafipour, E.; Loor, J.J. Linking Peripartal Dynamics of Ruminal Microbiota to Dietary Changes and Production Parameters. Front. Microbiol. 2016, 7, 2143. [CrossRef] [PubMed]

36. Plaizier, J.C.; Danesh Mesgaran, M.; Derakhshani, H.; Golder, H.; Khafipour, E.; Kleen, J.L.; Lean, I.; Loor, J.; Penner, G.; Zebeli, Q. Review: Enhancing Gastrointestinal Health in Dairy Cows. Anim. Int. J. Anim. Biosci. 2018, 12, s399-s418. [CrossRef]

37. Sylvester, J.T.; Karnati, S.K.R.; Dehority, B.A.; Morrison, M.; Smith, G.L.; St-Pierre, N.R.; Firkins, J.L. Rumen Ciliated Protozoa Decrease Generation Time and Adjust 18S Ribosomal DNA Copies to Adapt to Decreased Transfer Interval, Starvation, and Monensin. J. Dairy Sci. 2009, 92, 256-269. [CrossRef] [PubMed]

38. Firkins, J.L.; Yu, Z.; Park, T.; Plank, J.E. Extending Burk Dehority's Perspectives on the Role of Ciliate Protozoa in the Rumen. Front. Microbiol. 2020, 11, 123. [CrossRef] [PubMed] 
39. Silberberg, M.; Chaucheyras-Durand, F.; Commun, L.; Mialon, M.M.; Monteils, V.; Mosoni, P.; Morgavi, D.P.; Martin, C. Repeated Acidosis Challenges and Live Yeast Supplementation Shape Rumen Microbiota and Fermentations and Modulate Inflammatory Status in Sheep. Anim. Int. J. Anim. Biosci. 2013, 7, 1910-1920. [CrossRef]

40. Hess, M.; Paul, S.S.; Puniya, A.K.; van der Giezen, M.; Shaw, C.; Edwards, J.E.; Fliegerová, K. Anaerobic Fungi: Past, Present, and Future. Front. Microbiol. 2020, 11, 584893. [CrossRef] [PubMed]

41. Dieho, K.; van den Bogert, B.; Henderson, G.; Bannink, A.; Ramiro-Garcia, J.; Smidt, H.; Dijkstra, J. Changes in Rumen Microbiota Composition and in Situ Degradation Kinetics during the Dry Period and Early Lactation as Affected by Rate of Increase of Concentrate Allowance. J. Dairy Sci. 2017, 100, 2695-2710. [CrossRef]

42. Moraïs, S.; Mizrahi, I. Islands in the Stream: From Individual to Communal Fiber Degradation in the Rumen Ecosystem. FEMS Microbiol. Rev. 2019, 43, 362-379. [CrossRef] [PubMed]

43. Raut, M.P.; Couto, N.; Karunakaran, E.; Biggs, C.A.; Wright, P.C. Deciphering the Unique Cellulose Degradation Mechanism of the Ruminal Bacterium Fibrobacter Succinogenes S85. Sci. Rep. 2019, 9, 16542. [CrossRef]

44. Comtet-Marre, S.; Parisot, N.; Lepercq, P.; Chaucheyras-Durand, F.; Mosoni, P.; Peyretaillade, E.; Bayat, A.R.; Shingfield, K.J.; Peyret, P.; Forano, E. Metatranscriptomics Reveals the Active Bacterial and Eukaryotic Fibrolytic Communities in the Rumen of Dairy Cow Fed a Mixed Diet. Front. Microbiol. 2017, 8, 67. [CrossRef] [PubMed]

45. Chaucheyras-Durand, F.; Ameilbonne, A.; Auffret, P.; Bernard, M.; Mialon, M.-M.; Dunière, L.; Forano, E. Supplementation of Live Yeast Based Feed Additive in Early Life Promotes Rumen Microbial Colonization and Fibrolytic Potential in Lambs. Sci. Rep. 2019, 9, 19216. [CrossRef] [PubMed]

46. Mosoni, P.; Fonty, G.; Gouet, P. Competition between Ruminal Cellulolytic Bacteria for Adhesion to Cellulose. Curr. Microbiol. 1997, 35, 44-47. [CrossRef]

47. Shinkai, T.; Ohji, R.; Matsumoto, N.; Kobayashi, Y. Fibrolytic Capabilities of Ruminal Bacterium Fibrobacter Succinogenes in Relation to Its Phylogenetic Grouping. FEMS Microbiol. Lett. 2009, 294, 183-190. [CrossRef]

48. Suen, G.; Stevenson, D.M.; Bruce, D.C.; Chertkov, O.; Copeland, A.; Cheng, J.-F.; Detter, C.; Detter, J.C.; Goodwin, L.A.; Han, C.S.; et al. Complete Genome of the Cellulolytic Ruminal Bacterium Ruminococcus Albus 7. J. Bacteriol. 2011, 193, 5574-5575. [CrossRef] [PubMed]

49. Mousaie, A.; Valizadeh, R.; Chamsaz, M. Selenium-Methionine and Chromium-Methionine Supplementation of Sheep around Parturition: Impacts on Dam and Offspring Performance. Arch. Anim. Nutr. 2017, 71, 134-149. [CrossRef] [PubMed]

50. Castillo, C.; Hernández, J.; Bravo, A.; Lopez-Alonso, L.; Pereira, V.; Benedito, J. Oxidative Status during Late Pregnancy and Early Lactation in Dairy Cows. Vet. J. Lond. Engl. 1997 2005, 2, 286-292. [CrossRef] [PubMed]

51. Aydin, I.; Bulbul, T.; Polat, E.S.; Yazar, E. Serum Antioxidant Status and Adenosine Deaminase Activity during the Gestational Period of Sheep. Rev. Méd Vét 2010, 161, 479-484.

52. Mohebbi-Fani, M.; Mirzaei, A.; Nazifi, S.; Shabbooie, Z. Changes of Vitamins A, E, and C and Lipid Peroxidation Status of Breeding and Pregnant Sheep during Dry Seasons on Medium-to-Low Quality Forages. Trop. Anim. Health Prod. 2012, 44, 259-265. [CrossRef] [PubMed]

53. Bell, A.W. Regulation of Organic Nutrient Metabolism during Transition from Late Pregnancy to Early Lactation. J. Anim. Sci. 1995, 73, 2804-2819. [CrossRef] [PubMed]

54. Durand-Chaucheyras, F.; Fonty, G.; Bertin, G.; Théveniot, M.; Gouet, P. Fate of Levucell SC I-1077 Yeast Additive during Digestive Transit in Lambs. Reprod. Nutr. Dev. 1998, 38, 275-280. [CrossRef]

55. Chaucheyras Durand, F.; Duniere, L. The use of probiotics as supplements for ruminants. In Improving Rumen Function; Burleigh Dodds Science Publishing: Cambridge, UK, 2020; pp. 775-818. ISBN 978-1-78676-332-7.

56. Chaucheyras-Durand, F.; Ameilbonne, A.; Bichat, A.; Mosoni, P.; Ossa, F.; Forano, E. Live Yeasts Enhance Fibre Degradation in the Cow Rumen through an Increase in Plant Substrate Colonization by Fibrolytic Bacteria and Fungi. J. Appl. Microbiol. 2016, 120, 560-570. [CrossRef] [PubMed]

57. Martinez-Garcia, M.; Brazel, D.M.; Swan, B.K.; Arnosti, C.; Chain, P.S.G.; Reitenga, K.G.; Xie, G.; Poulton, N.J.; Lluesma Gomez, M.; Masland, D.E.D.; et al. Capturing Single Cell Genomes of Active Polysaccharide Degraders: An Unexpected Contribution of Verrucomicrobia. PLoS ONE 2012, 7, e35314. [CrossRef] [PubMed]

58. Kamke, J.; Kittelmann, S.; Soni, P.; Li, Y.; Tavendale, M.; Ganesh, S.; Janssen, P.H.; Shi, W.; Froula, J.; Rubin, E.M.; et al. Rumen Metagenome and Metatranscriptome Analyses of Low Methane Yield Sheep Reveals a Sharpea-Enriched Microbiome Characterised by Lactic Acid Formation and Utilisation. Microbiome 2016, 4, 56. [CrossRef] [PubMed]

59. Parra, M.C.; Costa, D.F.A.; Palma, A.S.V.; Camargo, K.D.V.; Lima, L.O.; Harper, K.J.; Meale, S.J.; Silva, L.F.P. The Use of Live Yeast to Increase Intake and Performance of Cattle Receiving Low-Quality Tropical Forages. J. Anim. Sci. 2021, 99. [CrossRef] [PubMed]

60. Lefler, J.; Minini, S.; Morandi, A.; Embree, M. Effect of Direct-Fed Microbial on Commercial Dairy Drylot; Elsevier Science Inc: New York, NY, USA, 2020; p. M132.

61. Oikonomou, G.; Teixeira, A.G.V.; Foditsch, C.; Bicalho, M.L.; Machado, V.S.; Bicalho, R.C. Fecal Microbial Diversity in Pre-Weaned Dairy Calves as Described by Pyrosequencing of Metagenomic 16S RDNA. Associations of Faecalibacterium Species with Health and Growth. PLoS ONE 2013, 8, e63157. [CrossRef] [PubMed]

62. Sordillo, L.M.; Raphael, W. Significance of Metabolic Stress, Lipid Mobilization, and Inflammation on Transition Cow Disorders. Vet. Clin. North Am. Food Anim. Pract. 2013, 29, 267-278. [CrossRef] 
63. Abuelo, Á.; Hernández, J.; Benedito, J.L.; Castillo, C. The Connexion between Serum Redox Balance and Concentration of Lactic Acid Enantiomers in Dairy Cows around the Time of Calving. Comp. Clin. Pathol. 2015, 24, 465-468. [CrossRef]

64. Cerretani, L.; Bendini, A. Chapter 67-Rapid Assays to Evaluate the Antioxidant Capacity of Phenols in Virgin Olive Oil. In Olives and Olive Oil in Health and Disease Prevention; Preedy, V.R., Watson, R.R., Eds.; Academic Press: San Diego, CA, USA, 2010; pp. 625-635. ISBN 978-0-12-374420-3.

65. Mavrommatis, A.; Mitsiopoulou, C.; Christodoulou, C.; Karabinas, D.; Nenov, V.; Zervas, G.; Tsiplakou, E. Dietary Supplementation of a Live Yeast Product on Dairy Sheep Milk Performance, Oxidative and Immune Status in Peripartum Period. J. Fungi. 2020, 6, 334. [CrossRef] [PubMed]

66. Doucet, M.; Sagot, L. Des Brebis Bien Nourries, Des Agneaux Plus Vigoureux; Institut De L'elevage: Paris, France, 2018 ; Volume 6.

67. Roca Fraga, F.J.; Lagisz, M.; Nakagawa, S.; Lopez-Villalobos, N.; Blair, H.T.; Kenyon, P.R. Meta-Analysis of Lamb Birth Weight as Influenced by Pregnancy Nutrition of Multiparous Ewes. J. Anim. Sci. 2018, 96, 1962-1977. [CrossRef] [PubMed]

68. Sales, F.; Peralta, O.A.; Narbona, E.; McCoard, S.; De Los Reyes, M.; González-Bulnes, A.; Parraguez, V.H. Hypoxia and Oxidative Stress Are Associated with Reduced Fetal Growth in Twin and Undernourished Sheep Pregnancies. Anim. Open Access J. MDPI 2018, 8, 217. [CrossRef]

69. Chang, H.C.; Leaw, S.N.; Huang, A.H.; Wu, T.L.; Chang, T.C. Rapid Identification of Yeasts in Positive Blood Cultures by a Multiplex PCR Method. J. Clin. Microbiol. 2001, 39, 3466-3471. [CrossRef] [PubMed]

70. Stevenson, D.M.; Weimer, P.J. Dominance of Prevotella and Low Abundance of Classical Ruminal Bacterial Species in the Bovine Rumen Revealed by Relative Quantification Real-Time PCR. Appl. Microbiol. Biotechnol. 2007, 75, 165-174. [CrossRef] [PubMed] 